\title{
Spray Pyrolysis Technique; High-K Dielectric Films and Luminescent Materials: A Review
}

\author{
Ciro Falcony ${ }^{1, *}$, Miguel Angel Aguilar-Frutis ${ }^{2}$ and Manuel García-Hipólito ${ }^{3}$ \\ 1 Departamento de Física, CINVESTAV, Apdo. Postal 14-470, Delegación Gustavo A. Madero, \\ Mexico City C.P. 07000, Mexico \\ 2 Instituto Politécnico Nacional, Centro de Investigación en Ciencia Aplicada y Tecnología Avanzada, \\ Legaría 694 Colonia Irrigación, Mexico City C.P. 11500, Mexico; mafrutis@yahoo.es \\ 3 Instituto de Investigaciones en Materiales, UNAM, Apdo. Postal 70-360, Delegación Coyoacán, \\ Mexico City C.P. 04150, Mexico; maga@unam.mx \\ * Correspondence: cfalcony@fis.cinvestav.mx; Tel.: +52-55-5747-3703
}

Received: 7 July 2018; Accepted: 23 July 2018; Published: 19 August 2018

\begin{abstract}
The spray pyrolysis technique has been extensively used to synthesize materials for a wide variety of applications such as micro and sub-micrometer dimension MOSFET's for integrated circuits technology, light emitting devices for displays, and solid-state lighting, planar waveguides and other multilayer structure devices for photonics. This technique is an atmospheric pressure chemical synthesis of materials, in which a precursor solution of chemical compounds in the proper solvent is sprayed and converted into powders or films through a pyrolysis process. The most common ways to generate the aerosol for the spraying process are by pneumatic and ultrasonic systems. The synthesis parameters are usually optimized for the materials optical, structural, electric and mechanical characteristics required. There are several reviews of the research efforts in which spray pyrolysis and the processes involved have been described in detail. This review is intended to focus on research work developed with this technique in relation to high- $K$ dielectric and luminescent materials in the form of coatings and powders as well as multiple layered structures.
\end{abstract}

Keywords: spray pyrolysis technique; dielectric materials; luminescent materials

\section{Introduction}

The spray pyrolysis technique is a low-cost, non-vacuum required, way to synthesize materials in the form of powders and films. In the case of films, they are usually deposited over a wide variety of substrates that can be easily adapted for large area deposition and industrial production processes [1-7]. A large amount of the work reported using this technique is concerned with semiconductors, metal and transparent conductive oxides (TCO's) related to their electrical conductivity characteristics. In particular, in the case of TCO's and their relevance for photovoltaic applications, a considerable amount of effort was set to optimize their optical transparency in the visible and electrical conductivity characteristics. This was the case for indium-tin oxides (ITO), indium-Zinc Oxide (IZO), fluorinated-tin oxide (FTO) and many others [1,3]. It was until a few decades ago that different metal oxide and compounds, mixed or in a multiple layer form, incorporating a large variety of dopants were synthesized by this technique for other application purposes [8-10]. Thus, coatings were developed to modify the optical absorption/transmittance, and emissivity of flat glass for the automotive, as well as construction industries. Furthermore, they were also developed for multiple layered structures, such as planar waveguides and resonant optical cavities for photonics [11-13], as well as semiconducting and metal oxide layers. These were doped with a variety of atomic and molecular centers, synthesized by this technique, for the development of light emission devices [14,15]. The dielectric characteristics of 
many metal oxides were also evaluated for high dielectric constant coatings for dielectric gate layers that might find applications in MOSFET technology, as well [16-20].

This technique is an atmospheric pressure chemical synthesis of materials, in which a precursor solution of chemical compounds in the proper solvent is sprayed through a furnace. In the case of powders, or on a hot substrate in the case of films, where a pyrolysis reaction is achieved, metal oxides is the preferred compound to be obtained by this technique. Nonetheless, metal and semiconductor materials have also been synthesized by a proper deposition ambient and carrier gas choice [1,15]. In this paper, a revision of the work involving the spray pyrolysis technique (published in the later period of time) will be presented. This focuses on the high- $K$ dielectric and luminescent properties of coatings and powders as well as multiple layered structures. This review will begin with a brief general description of the basic physical and chemical principles utilized by this technique, and the different experimental arrangements and deposition regimes that are involved in this process. The main characteristics of high- $K$ dielectric materials deposited on different type of substrates will then be discussed, as well as the luminescent characteristics of both powders and coatings of materials obtained by the incorporation of dopants in a suitable matrix.

\section{Spray Pyrolysis as Materials Synthesis Technique}

The spray pyrolysis technique involves three major process stages: Precursor solution composition, aerosol generation and transport, and synthesis process. Every one of these stages is tuned according to of the final chemical and physical characteristics of the material targeted; these adjustments and the choice of materials/processes at each stage will affect the rest of the stages, to some extent. Thus, at the first stage, the chemical composition of the precursor solution will have to involve a compound(s) that will render after the pyrolysis stage the chemical composition required. The selection of the solvent will limit the maximum concentration of the precursor compound in the solution and will determine the best choice for the aerosol generation/transport process and the temperature and rate of synthesis. At the second stage, the aerosol droplet size distribution, determined by the aerosol generation mechanism, will set the morphological characteristics of the final material produced, as well as the proper range of synthesis temperatures. The carrier gas nature and flux rate will propitiate or reduce the probability of a reactive interaction with the precursor compound. At the last stage, the decision whether the final chemical reaction takes place on a gas phase or on a hot substrate will determine if the material synthesized is a powder or a film coating. In general, given an experimental setup, the synthesis parameters that are more relevant are the concentration molarity of the precursor solution, the carrier gas flux rate, and the synthesis temperature.

The solvent in the precursor solution is chosen attending to the solubility of the precursor compound and on its physical properties such as density and viscosity as well as on the final byproducts that will generate and how neutral for their disposal they will be. The preferred choice is water or a mixture of water and an alcohol, which will dissolve many inorganic salts (such as chlorides, some nitrites and fluorides). Organic salts will require organic solvents that, when properly selected, could render excellent precursor solutions, especially for thin films deposition processes [4].

The aerosol generation mechanism could be as simple as a pneumatic system or a more complex but more tunable ultrasonic system. Figure 1 illustrates both systems. In the most common setup for a pneumatic system (Figure 1a), a Venturi nozzle is used in which the precursor solution is fed through a fine (capillary like) inlet into a pressurized carrier gas jet flow. An equation to estimate the average drop diameter has been developed for this type of nozzle [21]:

$$
d=0.64 D\left[1+0.011\left(\frac{G_{l}}{G_{g}}\right)^{2}\right]\left[\frac{2 \gamma}{\rho v^{2} D}\right]^{0.45}
$$

where; $G_{l}$ and $G_{g}$ represent the mass flow rate of liquid and gas, respectively, $\gamma$ the liquid surface tension, $\rho$ the density of the gas, $D$ the diameter of the spraying solution inlet orifice, and $v$ the velocity 
of gas. The actual experimental distribution of the droplet diameter size distribution generated by pneumatic means [3] is shown in Figure 1b, for the number of drops and for the total mass carried by the drops, in both cases a broad distribution is observed. Figure 1c shows a diagram of an ultrasonic system [5], in which the aerosol is generated by the ultrasonic waves produced with a piezoelectric disc in contact with the precursor solution. The standing waves generated at/near the surface of the liquid solution result in a generation of droplets in a combination of surface waves (capillary waves) and cavitation phenomena. The first mechanism dominates at low frequencies $(20-100 \mathrm{kHz})$ and the later at frequencies above $100 \mathrm{kHz}(0.1-5 \mathrm{MHz})$. An expression that estimates well the diameter of the droplets was derived [22] as follows:

$$
D=\left(\frac{\pi \sigma}{\rho f^{2}}\right)^{1 / 3}+0.0013(W e)^{0.008}(O h)^{-0.14 / n}\left(I_{N}\right)^{-0.28}
$$

where

$$
\begin{gathered}
W e=\frac{f Q \rho}{\sigma} \\
O h=\frac{\mu}{f \cdot A_{m}^{2} \rho}
\end{gathered}
$$

And

$$
I_{N}=\frac{f^{2} A_{m}^{4}}{v_{s} Q}
$$

In these expressions; $f$ is the ultrasonic wave frequency, $A_{m}$ is the amplitude, $\sigma$ is the surface tension, $\rho$ is the liquid density, $\mu$ is the viscosity and $Q$ is the volumetric flow rate of the liquid and $v_{s}$ is the speed of sound. Figure $1 \mathrm{~d}$ shows the experimental distribution for the number of drops and for the total mass carried by the drops generated by ultrasound waves at three different frequencies: $0.7,0.115$, and $3 \mathrm{MHz}$. The narrow distribution of drops, as well as the control on the average size, is considered the main advantages of the ultrasonic aerosol generation systems. Once the aerosol mist is generated, it has to be transported to the material synthesis area, since in most cases the droplets in the aerosol are below $20 \mu \mathrm{m}$ in diameter, they can be carried with a gas flow set to minimize coalescence of the drops throughout the transport process, and also to render a desired synthesis rate. Since the carrier gas will be closely present during the synthesis process, whether it is chosen to be an inert or a reactive gas becomes relevant. Thus, if the carrier gas is air, the synthesis is limited to compounds that are as stable like or even better than oxides. In the case of metals, the carrier gas has to be an inert gas which in some cases is combined with a reduction gas $\left(\mathrm{N}_{2}\right.$ and $\mathrm{H}_{2}$, as in the case of forming gas) [1].

At the reactive zone, several parameters are determinant as to what type of material synthesis process occurs, such as temperature, droplet size and their speed. The reactive zone is, in the case of film deposition, the space near the surface of the hot substrate (a few millimeters above the surface of the substrate), or the furnace heated chamber, in the case of powder synthesis. Figure 2 shows a diagram of the different stages at which the droplet is subjected as it approaches the hot substrate for two cases a fixed droplet size and speed, different (increasing from A to D, Figure 2a) temperature of the substrate and fixed substrate temperature and speed of different droplet sizes (decreasing droplet size from A to D, Figure 2b) [23,24]. At low temperature (large initial droplet size), the solvent within the droplet is not completely vaporized and the liquid droplet hits the substrate and upon contact with it vaporizes leaving a ring-shaped dry precipitate on the substrate (process A). At low or intermediate temperature values (large or medium droplet size) the solvent is vaporized, and a dry precipitate (an amorphous precursor salt) hits the substrate surface where a pyrolysis reaction takes place (process B). At intermediate or high temperatures (medium or small droplet size) the droplet goes through all previously described stages. Near the substrate surface the dry precipitates are vaporized, propitiating a chemical vapor reaction (CVD) on the surface of the substrate (process C). Finally, for high temperature (small droplet sizes) the vaporized precipitates undergo a chemical reaction in the vapor phase before they reach the substrate surface (process D). In the case powder 
synthesis, similar processes occur-but for this case, the parameter that controls the occurrence of the different synthesis stages is the time of flight (time of residence) of the droplet inside the hot zone of the furnace [5].

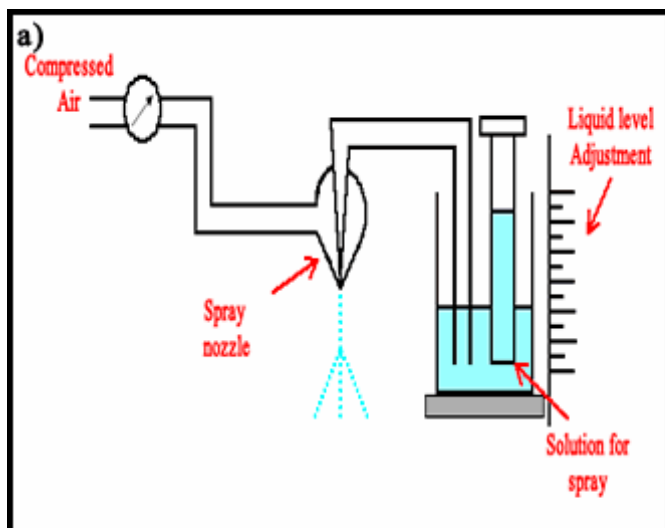

c)

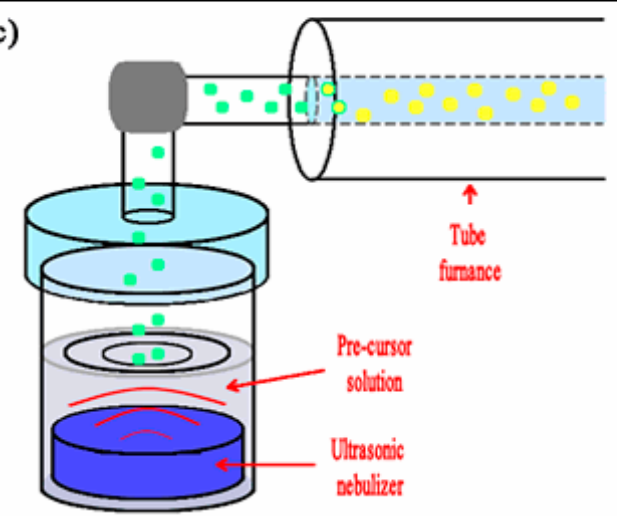

b)

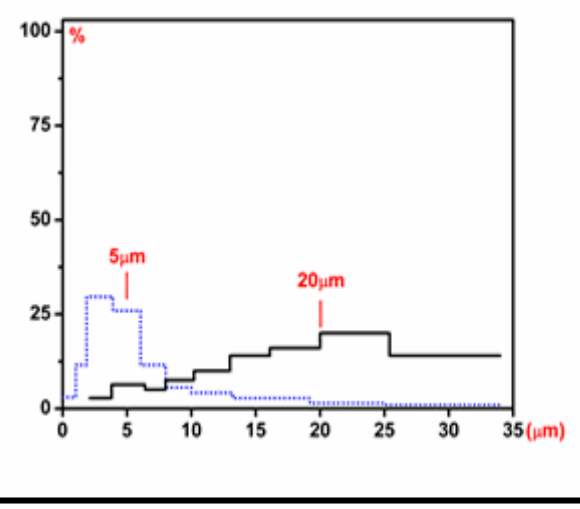

d)

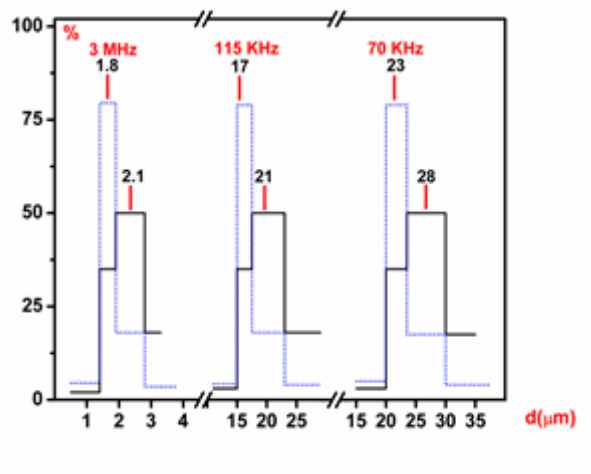

Figure 1. The most common aerosol generation systems, pneumatic and ultrasonic, and the droplet distribution by diameter size or by the amount of solution delivered: (a) Shows the pneumatic setup, and (b) the corresponding droplet distribution. (c) Shows the ultrasonic system, and (d) the droplet distribution for this system.

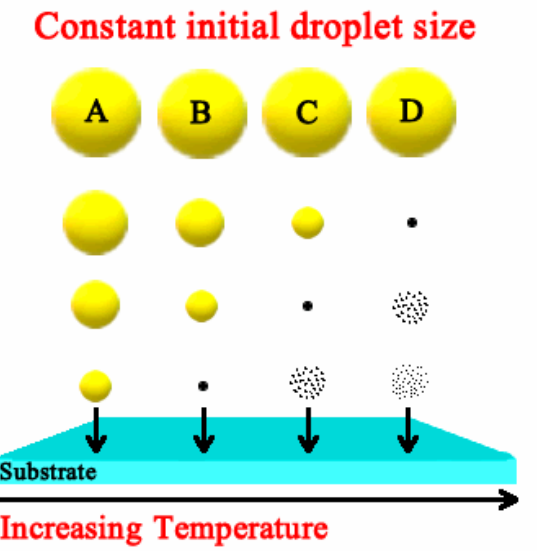

(a)

\section{Decreasing initial droplet size}

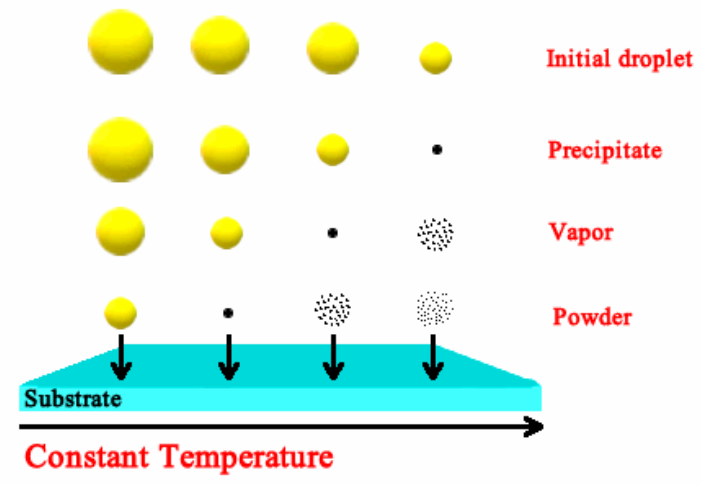

(b)

Figure 2. Diagram of the different process stages for the aerosol droplet evolution as it approaches the hot substrate for two cases: (a) Constant initial droplet size and increasing substrate temperature, and $(\mathbf{b})$ constant substrate temperature and decreasing initial droplet size. 


\section{High-K Dielectric Films}

Results associated to the fabrication and characterization of high- $K$ dielectrics obtained by ultrasonic spray pyrolysis (USP) is shown in this section. The synthesis of high-K dielectric thin films by USP is considered of great importance because, as can be inferred from the last section, the technique is neither expensive nor difficult to be developed in any fair laboratory [2]. Several high- $K$ dielectrics have been attempted, including aluminum oxide thin films, zirconium oxide, and yttrium oxide [16-20]. The main goal of researching high- $K$ dielectrics is the preparation of metal oxides that might be of interest for the scaling and gate capacitance of some devices in the future. Literature has shown clearly the need to develop high- $K$ dielectric materials $[25,26]$ for electronic microdevices in the silicon based Complementary Metal Oxide Semiconductor (CMOS) technology. This is the case of Field Effect Transistors (FETs), one of the most important devices, because of its low power consumption and performance. However, the need of down scaling has been a very dramatic issue. Furthermore, the materials involved for these applications show a dramatic constraint in the dielectric layers that play an important role in the FETs. In them, the thickness of the $\mathrm{SiO}_{2}$ layer needed for the gate dielectric is under $1.4 \mathrm{~nm}$; so thin that the gate leakage current by direct tunneling of electrons through the $\mathrm{SiO}_{2}$ film becomes too high. This, and other drawbacks, have resulted in a search for better suited dielectric materials than that of $\mathrm{SiO}_{2}$. Since the tunneling current across a dielectric film decreases exponentially with increasing thickness ( $\Im \propto \exp \left(-2 \sqrt{\frac{2 m \phi}{\hbar^{2}}} z\right.$ ), where $\phi$ is the barrier height for tunneling), a thicker layer of a higher dielectric constant material than $\mathrm{SiO}_{2}$ is a possible solution. In a FET, the source-drain current depends on the gate capacitance: $C=\frac{k \epsilon_{0} A}{t}$, where $\epsilon_{0}$ is the permittivity of free space, $k$ is the relative permittivity, $A$ is the area and $t$ is the oxide thickness. So, to solve the problem of leakage current due to tunneling, it is required to replace $\mathrm{SiO}_{2}$ with a physically thicker layer of a higher dielectric constant material. This would preserve the capacitance value with a reduced tunneling current. With this purpose in mind, the "equivalent oxide thickness", (EOT), defined as $t_{o x}=\left(\frac{3.9}{K}\right) t_{h i K}$, where the 3.9 value is the dielectric constant of $\mathrm{SiO}_{2}$, has been used as a figure of merit for high- $K$ dielectrics to be used instead $\mathrm{SiO}_{2}$. The requirements for choosing a new high $K$ dielectric are the following: (i) Its $K$ value must be high enough. (ii) The oxide should be thermodynamically stable when in contact with the Si channel. (iii) It must act as an insulator (large barrier with Si for both holes and electrons), and (iv) It should have a good electrical interface with Si. The static dielectric constant of high- $K$ oxides is already known. Some oxides with its dielectric constant are listed in Table $1[25,26]$.

Table 1. Static dielectric constant of a few gate dielectrics.

\begin{tabular}{cc}
\hline Oxide & $\boldsymbol{K}$ \\
\hline $\mathrm{SiO}_{2}$ & 3.9 \\
$\mathrm{Si}_{3} \mathrm{~N}_{4}$ & 7 \\
$\mathrm{Al}_{2} \mathrm{O}_{3}$ & 9 \\
$\mathrm{Ta}_{2} \mathrm{O}_{5}$ & 22 \\
$\mathrm{TiO}_{2}$ & 80 \\
$\mathrm{ZrO}_{2}$ & 25 \\
$\mathrm{HfO}_{2}$ & 25 \\
$\mathrm{HfSiO}_{4}$ & 11 \\
$\mathrm{La}_{2} \mathrm{O}_{3}$ & 30 \\
$\mathrm{Y}_{2} \mathrm{O}_{3}$ & 15 \\
a- $\mathrm{LaAlO}_{3}$ & 30 \\
\hline
\end{tabular}

\subsection{High-K Dielectrics Materials}

Some common high- $K$ metal oxides that might provide thicker dielectric layers with reduced leakage (preserving the $\mathrm{SiO}_{2}$ equivalent capacitance values) are $\mathrm{Ta}_{2} \mathrm{O}_{5}, \mathrm{SrTiO}_{3}, \mathrm{Al}_{2} \mathrm{O}_{3}$ (among others). These metal oxides' dielectric constants range from $\sim 10$ to 80 , and have been employed mainly in memory capacitor applications. Among the few high- $K$ materials above mentioned, $\mathrm{Al}_{2} \mathrm{O}_{3}$ is 
thermodynamically more stable when in contact with $\mathrm{Si}$ [26]. Before listing the synthesis and properties of aluminum oxide and other dielectrics prepared by the USP technique, it is important to realize the role of reagents and solvents involved in their synthesis.

\subsection{The Role of the Reagents and Solvents in the USP Synthesis of High-K Dielectric Layers}

The role of the reagents and solvents play a dramatic factor for achieving specific properties of films and coatings deposited by the USP technique [2]. Thus, it is important to revise the deposition process pathways, in particular, at the reactive stage (Figure 2). In the aerosol processing of materials, reactions are initiated by thermal energy. A wide number of metal-organic compounds have been used as precursors to a number of materials, via thermally induced aerosol processing. Among others, $\beta$-diketonates, carboxylates, alkoxides, and amides are frequently used. Metal $\beta$-diketonates and amides are often used as sources of metal-containing materials and frequently require reaction with an added reagent. Some metal alkoxides, $\beta$-diketonates, and amides sublimate, thus, these species are ideal and have been used for CVD like, or aerosol assisted CVD (process C in Figure 2) deposition process, that renders excellent quality layers. Metal $\beta$-diketonates have been utilized for the deposition of a large variety of materials, such as metals, metal oxides, and metal sulfides. The suggested reaction in the presence of water that produces metal oxides (MO) is as follows:

$$
\mathrm{M}(\beta-\text { diketonate })_{2}+\mathrm{H}_{2} \mathrm{O} \rightarrow \mathrm{MO}+2 \mathrm{H}(\beta-\text { diketonate })
$$

Organometallic compounds have been used extensively in the gas-phase synthesis of materials, particularly CVD and gas-to-particle conversion, because these compounds are often sufficiently volatile. In addition to the appropriate choice of an appropriate source of the metal, the selection of an appropriate solvent is also important. Three basic requirements should be accomplished by a solvent for its suitability in the case of ultrasonic generation of an aerosol. Firstly, the solubility of the acetylacetonates or the organometallic compounds used. The second requirement is, because of the requirement that the aerosol droplets should arrive near the substrate surface preferably in liquid state, that the solvent used should have a relatively high boiling point. The third requirement is that the solvent should also possess a low grade of viscosity to enable proper ultrasonic excitation and aerosol generation [11]. Atomization of acetylacetonates (dissolved in organic solvents) by ultrasonic excitation has been used by $\mathrm{G}$. Blandenet et al. to deposit films of $\mathrm{Al}_{2} \mathrm{O}_{3}, \mathrm{Y}_{2} \mathrm{O}_{3}, \mathrm{ZrO}_{2}$ and other coatings on glass and stainless steel [3].

The physical properties of a few solvents used during the deposition of some high- $K$ dielectric coatings in this work and in for other authors are listed in Table 2. In this review, it is highlighted the use of Dimethylformamide and a few alcohols [11].

Table 2. Physical properties of a few solvents used during the deposition of some high- $K$ dielectrics.

\begin{tabular}{ccccc}
\hline Solvent & $\begin{array}{c}\text { Boiling } \\
\text { Point }\left({ }^{\circ} \mathbf{C}\right)\end{array}$ & $\begin{array}{c}\text { Viscosity at Room } \\
\text { Temperature (mPas) }\end{array}$ & $\begin{array}{c}\text { Density } \\
\left(\mathbf{g} / \mathbf{c m}^{3}\right)\end{array}$ & Chemical Formula \\
\hline Dimethylformamide & 153.0 & 0.80 & 0.95 & $\mathrm{C}_{3} \mathrm{H}_{7} \mathrm{NO}$ \\
Methanol (Methyl Alcohol) & 65.0 & 0.52 & 0.79 & $\mathrm{CH}_{3} \mathrm{OH}$ \\
Ethanol (Ethyl Alcohol) & 78.5 & 1.19 & 0.78 & $\mathrm{CH}_{3} \mathrm{CH}_{2} \mathrm{OH}$ \\
Propanol (n-Propyl Alcohol) & 97.4 & 2.25 & 0.80 & $\mathrm{CH}_{3}\left(\mathrm{CH}_{2}\right)_{2} \mathrm{OH}$ \\
Butanol (n-Butyl Alcohol) & 117.0 & 2.95 & 0.80 & $\mathrm{CH}_{3}\left(\mathrm{CH}_{2}\right)_{2} \mathrm{CH}_{2} \mathrm{OH}$ \\
\hline
\end{tabular}

\subsection{Synthesis of $\mathrm{Al}_{2} \mathrm{O}_{3}$ Thin Films by USP Technique}

Aluminum oxide thin films $\left(\mathrm{Al}_{2} \mathrm{O}_{3}\right)$ have good thermal conductivity, low permeability to alkali ions, excellent hardness, high radiation resistance, high refractive index, high transparency, resistant against hostile environments and high dielectric constant [9,20,27-29]. This latter property is highly important to possibly replacement of $\mathrm{SiO}_{2}$ as a $\mathrm{H}-\mathrm{K}$ dielectric for the microelectronic devices 
applications. The fabrication of aluminum oxide thin films using the USP technique has been reported, at least, since the 1980s. G. Blandenet et al. deposited $\mathrm{Al}_{2} \mathrm{O}_{3}$ coatings on glass by ultrasonic spraying using aluminum isopropoxide, as source of aluminum, and butanol as solvent [3]. A lot of work has been carried out since then to get this type of films with improved characteristics. Actually, the research in these films continues up to date, using the same technique and/or a related spray pyrolysis technique. It is worth to mention the recent work of B.P. Dhonge et al. [30]; or the work of A.B. Khatibani et al., who also obtained alumina thin films by spray pyrolysis [31]. In particular, excellent quality aluminum oxide thin films have been deposited using aluminum acetylacetonate, dissolved in $N, N$-dimethylformamide as spraying solution $[9,19,20]$. These work shows the versatility of USP technique and how the experimental conditions of synthesis can be optimized to get the films with the required optical, structural and dielectric properties. A few highlights of these results are described below.

\subsection{Experimental Details}

The most appropriate reagent and solvent were found to be: Aluminum acetylacetonate $\left(\mathrm{Al}(\mathrm{acac})_{3}\right)$ as source of aluminum, and $N, N$-dimethylformamide (DMF) as solvent. Several solutions of $\mathrm{Al}(\mathrm{acac})_{3}$ in DMF were prepared. The solutions prepared consisted in dissolving 1, 3, 5, 7, 10 and $12 \mathrm{~g}$ of $\mathrm{Al}(\mathrm{acac})_{3}$ in $100 \mathrm{~mL}$ of DMF. The versatility of the spray pyrolysis process permits the generation of aerosol streams with different reagents and/or additives that can be supplied simultaneously during the synthesis of a thin film (for example, binary oxides of some semiconductors; such as $\mathrm{CuCrO}_{2}$ have been deposited within this approach [32]). In the present case, a parallel aerosol stream of water mist to the aerosol of the $\mathrm{Al}(\mathrm{acac})_{3}$ in DMF solution was supplied during the synthesis of the $\mathrm{Al}_{2} \mathrm{O}_{3}$ thin films. The motivation to use a water aerosol was realized by the report of J.S. Kim et al. [33], who used the addition of a water mist for fabricating thin films by the CVD method. The $\mathrm{Al}_{2} \mathrm{O}_{3}$ films were deposited on n-type silicon wafers of low and high resistivity $(0.1$ and $200 \Omega \cdot \mathrm{cm}$, respectively), and on quartz slides for the optical absorption measurements. The deposition of the films was achieved at different substrate temperatures: 450, 500, 550, 600 and $650{ }^{\circ} \mathrm{C}$. The high deposition rate of the films led to get the film thicknesses, within a few seconds or minutes, in the range of 90-130 $\mathrm{nm}$. MOS (Metal-Oxide-Semiconductor) structures were fabricated with these films by thermally evaporating aluminum contacts $\left(1.1 \times 10^{-2} \mathrm{~cm}^{2}\right)$ on top of the aluminum oxide thin film deposited on the silicon substrates $[9,19,20]$. The films resulted transparent in the whole visible range of the electromagnetic spectrum. The optical band gap of these films (about $5.63 \mathrm{eV}$ ) compared favorably to the best quality films obtained by other techniques. The films were found to be mainly amorphous in all cases. The films deposited with water mist showed a higher index of refraction, in contrast to the films deposited without water mist. These results might indicate that the films deposited by water mist show a higher specific density and were confirmed by the electrical response of the films, since the MOS structures fabricated with this type of films showed the best dielectric characteristics. The role of water during deposition process was perhaps to collect and remove the residual carbon from the acetylacetonate decomposition, reducing in this way the total amount of carbon and impurities that might remain in the oxide film $[9,19,20] .1 \mathrm{MHz}$ and quasi-static capacitance versus voltage characteristic of the MOS structures were used to determine the density of interface states that was found in the range of $10^{11} \mathrm{eV}^{-1} \cdot \mathrm{cm}^{-2}$. This density of interface states compared favorably to other dielectric layer used in many microelectronic applications. The current density measured by the ramp $\mathrm{I}-\mathrm{V}$ characteristic curves in these MOS structures, at electric fields below $2 \mathrm{MV} / \mathrm{cm}$, was in the range of the displacement current generated by the voltage ramp applied to the MOS structure $10^{-9} \mathrm{Amp} / \mathrm{cm}^{2}$. At electric fields higher than $2 \mathrm{MV} / \mathrm{cm}$ a real current injection across the aluminum oxide (produced by Fowler-Nordheim tunneling) increases up to $10^{-6} \mathrm{Amp} / \mathrm{cm}^{2}$ at approximately $5 \mathrm{MV} / \mathrm{cm}$ without any destructive breakdown of the films $[9,20]$. In addition, aluminum oxide thin films as thin as $30 \mathrm{~nm}$ were deposited by means of a pulsed spraying setup with excellent properties [19]. This last feature 
showed that the ultrasonic spraying is also capable of depositing extremely thin films of aluminum oxide preserving its excellent dielectric properties.

\section{5. $\mathrm{Y}_{2} \mathrm{O}_{3}$ and $\mathrm{ZrO}_{2}$ Films}

Other dielectrics have also been considered. In particular, yttrium, zirconium and silicon oxides $\left(\mathrm{Y}_{2} \mathrm{O}_{3}, \mathrm{ZrO}_{2}\right.$ and $\left.\mathrm{SiO}_{2}\right)$ deposited by spray pyrolysis. Even though $\mathrm{SiO}_{2}$ is not a high- $K$ dielectric, this type of film has been obtained successfully using the spray pyrolysis technique [18]. Other high- $K$ dielectrics, such as yttrium oxide thin films, have been deposited on silicon substrates using yttrium acetylacetonate as source of yttrium, and $\mathrm{N}, \mathrm{N}$-dimethylformamide as solvent. For this system, a solution of $\mathrm{H}_{2} \mathrm{O}-\mathrm{NH}_{4} \mathrm{OH}$ was sprayed in parallel during the deposition process to improve the optical, structural and electrical properties of the deposited films. In this case, the films were deposited at temperatures in the range from 400 to $550{ }^{\circ} \mathrm{C}$. The effective index of refraction measured in the films was about 1.86 , and an average deposition rate $\sim 0.1 \mathrm{~nm} / \mathrm{s}$. A highly textured surface of the films was obtained to (400) orientation. The growth of a $\mathrm{SiO}_{2}$ layer sandwiched between the yttrium oxide and the Si substrate was also noticed and it seemed to improve a lower interface state density, in the range of $10^{10} \mathrm{eV}^{-1} \cdot \mathrm{cm}^{-2}$. An effective dielectric constant up to 13, as well as a dielectric strength in the range of $0.2 \mathrm{MV} / \mathrm{cm}$ was obtained in a $100 \mathrm{~nm}$ thick film incorporated in a MOS structure. For this system, it seemed that the polycrystalline nature of these films results in a deterioration of the dielectric properties by reducing the threshold voltage needed for conduction current across the films [16,34]. Another high- $K$ dielectric that has been studied is zirconium oxide $\left(\mathrm{ZrO}_{2}\right) \cdot \mathrm{ZrO}_{2}$ thin films were also deposited on silicon substrates by spray pyrolysis, in the temperature range from 400 to $600{ }^{\circ} \mathrm{C}$. The use of zirconium acetylacetonate as source of zirconium and $N, N$-dimethylformamide was also used in this case. The films resulted with an index of refraction in the range of 2.12. The dielectric constant was about 12.5-17.5. In the best case, the films could stand an electric field up to $3 \mathrm{MV} / \mathrm{cm}$, without presenting evidences a dielectric breakdown. Transmission electron microscopy measurements indicated that the films of $\mathrm{ZrO}_{2}$ were constituted by nano-crystals embedded in an amorphous matrix [16].

In summary, high quality aluminum, yttrium and zirconium oxide thin films have been deposited by spray pyrolysis using acetylacetonates dissolved in $\mathrm{N}, \mathrm{N}$-dimethylformamide. In the case of aluminum oxide, they were obtained with excellent homogeneity to thicknesses down to $30 \mathrm{~nm}$. The addition of a parallel stream of water mist into the spraying solution aerosol during the deposition process resulted in a dramatic effect over the refractive index and on the dielectric characteristics of the deposited aluminum oxide films. The density of states in the range of $10^{11} \mathrm{eV}^{-1} \cdot \mathrm{cm}^{-2}$ and a destructive electric breakdown field larger than $5 \mathrm{MV} / \mathrm{cm}$, were obtained on MOS structures fabricated with these films. Yttrium and Zirconium oxide thin films showed a higher dielectric constant than those of aluminum oxide, but lower dielectric strength, likely due to the polycrystalline nature of the films.

\section{Luminescent Materials}

Luminescent materials, in the form of powders (phosphors) and films, have been extensively studied in recent decades $[35,36]$ because their great importance for a wide variety of applications such as: Lighting, image displays, signaling, lasers, medical applications, etc. [37,38]. They have been synthesized through a variety of physical and chemical techniques, including: Hidrothermal/Solvothermal [39-41], solid-state reaction [42], sol-gel [43,44], laser ablation [45,46], sputtering [47], Pechini Method [48], plasma electrolitic oxidation [49], conventional melt-quenching method [50,51], combustion synthesis [52], solvent evaporation method [53-55], and co-precipitation process [56]. Among these techniques, spray pyrolysis began to be used for this purpose in the mid-1980s, and it is still used today [57,58] — proving to be a practical, low cost, easy to extrapolate for large area deposition technique. In this review, an account is made on diverse luminescent materials synthesized by this technique. These materials in general involve one or more luminescent centers 
incorporated as dopants in a host lattice. A great variety of host lattices have been used for the synthesis (by means of spray pyrolysis) of phosphors and luminescent films, among them stand out metal oxides such as: $\mathrm{ZrO}_{2}, \mathrm{Al}_{2} \mathrm{O}_{3}, \mathrm{HfO}_{2}, \mathrm{Y}_{2} \mathrm{O}_{3}, \mathrm{ZnO}, \mathrm{In}_{2} \mathrm{O}_{3}, \mathrm{ZnSiO}, \mathrm{CdO},(\mathrm{Y}, \mathrm{Gd}) \mathrm{BO}_{3}, \mathrm{Gd}_{2} \mathrm{O}_{3}$, $\mathrm{LaPO}_{4}, \mathrm{BaMgAl}_{10} \mathrm{O}_{17}$, and some sulfur based compounds such as: $\mathrm{ZnS}, \mathrm{CaSO}_{4}, \mathrm{CdS}$, and others. The luminescent active centers have been mainly RE (Rare Earth) and some transition metal ions. In some cases, luminescence emission has been observed to be generated by mechanisms that involve structural defects and intrinsic states in the host lattices as well. This review focuses mainly on the work done on host lattices such as: $\mathrm{ZrO}_{2}, \mathrm{Al}_{2} \mathrm{O}_{3}, \mathrm{HfO}_{2}, \mathrm{Y}_{2} \mathrm{O}_{3}, \mathrm{ZnO}$, and $\mathrm{ZnS}$ with different dopants.

\section{1. $\mathrm{ZrO}_{2}$}

Virtually before 1999, $\mathrm{ZrO}_{2}$ had not been used as a host lattice to produce phosphor materials synthesized by spray pyrolysis technique. In that year, some results were reported about photoluminescence (PL) and thermoluminescence (TL) properties of $\mathrm{ZrO}_{2}: \mathrm{Tb}^{3+}$ films deposited by a pneumatic spray pyrolysis (PSP) system [59]. These films excited by $275 \mathrm{~nm}$ exhibited four peaks at 487 , 542,582 , and $619 \mathrm{~nm}$ - typical of electronic transitions in the $\mathrm{Tb}^{3+}$ ions. The TL glow curve displayed two peaks at $112{ }^{\circ} \mathrm{C}$ and $270{ }^{\circ} \mathrm{C}$ for the $\mathrm{ZrO}_{2}: \mathrm{Tb}^{3+}$ films exposed to $260 \mathrm{~nm}$ UV radiations. In addition, the TL response was linear in the range of 40 to $240 \mathrm{~mJ} \cdot \mathrm{cm}^{-2}$ spectral UV irradiance. These results exhibited that $\mathrm{ZrO}_{2}: \mathrm{Tb}^{3+}$ films had appropriate characteristics for their use as a UV dosimeter as well as PL phosphor. In a later investigation (2001) on this material [60], a deeper analysis was made on the thermoluminescence mechanisms. Two important parameters in TL studies such as activation energy (E) and the frequency factor (S) were investigated. In this contribution, the Lushchik and Chen methods were used to determine the kinetic parameters which showed second order kinetics for both the first and second glow TL peaks.

Furthermore, in 2001, PL and cathodoluminescence (CL) feature of $\mathrm{ZrO}_{2}: \mathrm{Tb}^{3+}$ films, deposited by the PSP, technique was reported [61]. In this case different deposition parameters, such as substrate temperatures, doping concentrations, and the flow of the precursor solution, were studied. Substrate temperatures higher than $400{ }^{\circ} \mathrm{C}$ rendered a polycrystalline material with metastable tetragonal or cubic phases. With increasing deposition temperatures, the PL and CL emission intensities (excited with $250 \mathrm{~nm}$ light) also increased. The PL and CL emission spectra showed the characteristic peaks associated with the electronic transitions of $\mathrm{Tb}^{3+}$ ions. Concentration quenching for the PL and CL emissions occurred at doping concentration greater than 1.96 and 1.17 at.\%, respectively. Similar studies were conducted on $\mathrm{ZrO}_{2}: \mathrm{Eu}^{3+}$ films [62]. Depending on the substrate temperature, these films were amorphous or polycrystalline (tetragonal-cubic phase). A strong red emission was observed which was generated by the ${ }^{5} \mathrm{D}_{0} \rightarrow{ }^{7} \mathrm{~F}_{2}$ transition typical of the $\mathrm{Eu}^{3+}$ ions. From those studies, it became clear that zirconia was a suitable host lattice for RE ions.

For the first time, a study on luminescent emissions from $\mathrm{ZrO}_{2}: \mathrm{Mn}^{2+}$ films deposited by the USP technique was reported in 2002 [63]. These films were deposited at substrate temperatures ranging from 250 to $500{ }^{\circ} \mathrm{C}$. The PL and CL $(7 \mathrm{KeV})$ emission spectra showed a broad band $(450-750 \mathrm{~nm})$ centered at $650 \mathrm{~nm}$ (red), which is associated with the electronic transitions ${ }^{4} \mathrm{~T}_{1}\left({ }^{4} \mathrm{G}\right) \rightarrow{ }^{6} \mathrm{~A}_{1}\left({ }^{6} \mathrm{~S}\right)$ of the $\mathrm{Mn}^{2+}$ ions. A decrease of the luminescence, as a function of the doping concentration, substrate temperature and electron accelerating voltage was observed. The maximum emission intensity was observed for films deposited at $250{ }^{\circ} \mathrm{C}$, EDS measurements showed that these films had a high amount of incorporated chlorine (from the precursors in the spraying solution), which acts as a co-activator for the red emission. As the deposition temperature increased, the amount of chlorine in the film (as well as the red luminescence emission intensity) decreased. The presence of chlorine was necessary for the red luminescence emission to occur. CL spectra obtained at higher electron accelerating voltages $(10 \mathrm{KeV})$ from samples deposited at $500{ }^{\circ} \mathrm{C}$ showed, instead of the red emission, a wide band centered at $590 \mathrm{~nm}$ (yellow) - which is also characteristic of $\mathrm{Mn}^{2+}$ ions.

$\mathrm{ZrO}_{2}: \mathrm{Eu}^{3+}$ phosphors consisting of spherical, dense and sub-micrometer size particles were successfully synthesized by the USP technique in 2005 [64]. The X-ray diffraction (XRD) measurements 
indicated that the crystallinity of these powders increased with increasing postdeposition annealing temperature. Several characterization techniques were used to study this material: Including PL emission spectra, and decay time measurements. The excitation spectrum showed a band centered at $248 \mathrm{~nm}$ corresponding to a charge transfer transition from Eu-O generated electronic states in the $\mathrm{ZrO}_{2}$ host matrix. The emission spectra exhibit the typical (red) bands of $\mathrm{Eu}^{3+}$ ions. The optimal concentration of $\mathrm{Eu}^{3+}$ ions was 10 at.\% and it was observed that the spherical morphology of the particles improves the intensity of the PL emission.

A research work on $\mathrm{ZrO}_{2}: \mathrm{Pr}^{3+}$ films was published in 2007 [65]. In this case, PL and CL properties were studied as a function of growth parameters such as the substrate temperature and the $\operatorname{Pr}^{3+}$ ions concentration. XRD studies indicated a tetragonal crystalline structure for zirconia as the substrate temperature was increased. The PL spectra exhibited bands centered at 490, 510, 566, $615,642,695,718,740$ and $833 \mathrm{~nm}$; associated with the electronic transitions ${ }^{3} \mathrm{P}_{0} \rightarrow{ }^{3} \mathrm{H}_{4},{ }^{3} \mathrm{P}_{0} \rightarrow{ }^{3} \mathrm{H}_{4}$, ${ }^{3} \mathrm{P}_{1}+{ }^{1} \mathrm{I}_{6} \rightarrow{ }^{3} \mathrm{H}_{5},{ }^{1} \mathrm{D}_{2} \rightarrow{ }^{3} \mathrm{H}_{4},{ }^{3} \mathrm{P}_{0} \rightarrow{ }^{3} \mathrm{H}_{6},{ }^{1} \mathrm{D}_{2} \rightarrow{ }^{3} \mathrm{H}_{5},{ }^{1} \mathrm{D}_{2} \rightarrow{ }^{3} \mathrm{H}_{5},{ }^{3} \mathrm{P}_{0} \rightarrow{ }^{3} \mathrm{~F}_{3,4}$, and ${ }^{1} \mathrm{D}_{2} \rightarrow{ }^{3} \mathrm{~F}_{2}$ of the $\mathrm{Pr}^{3+}$ ions. As the substrate temperature was increased, an increasing intensity of the PL emission was observed. Also, a quenching of the PL and CL emissions, with increasing doping concentration, was detected. Interestingly the CL spectra, as a function of the electron accelerating voltage, showed an evolution of the highest peak: For low electron accelerating voltages $(4 \mathrm{kV})$ the red emission $(615 \mathrm{~nm})$ is the maximum, and for high voltages $(15 \mathrm{kV})$ the most intense band is the blue (around $490 \mathrm{~nm}$ ).

The cathodoluminescence properties of $\mathrm{ZrO}_{2}: \mathrm{Er}^{3+}$ films were reported in 2014 [66]. These films were deposited at different temperatures from $400{ }^{\circ} \mathrm{C}$ up to $550{ }^{\circ} \mathrm{C}$. As substrate temperatures are increased, the films showed a tetragonal phase. CL emission spectra showed bands centered at 524 (green), 544 (green) and 655 (red) nm associated with the electronic transition ${ }^{2} \mathrm{H}_{11 / 2} \rightarrow{ }^{4} \mathrm{I}_{11 / 2}$, ${ }^{4} \mathrm{~S}_{3 / 2} \rightarrow{ }^{4} \mathrm{I}_{15 / 2}$, and ${ }^{4} \mathrm{~F}_{9 / 2} \rightarrow{ }^{4} \mathrm{I}_{15 / 2}$ of $\mathrm{Er}^{3+}$ ions. The highest emission intensity is achieved in samples deposited at $500{ }^{\circ} \mathrm{C}$ doped with 5 at.\% of $\mathrm{Er}^{3+}$ ions. Also, the CL emission intensity increases as the substrate temperature and electron accelerating voltage values increase.

Investigations on $\mathrm{ZrO}_{2}: \mathrm{Dy}^{3+}$ and $\mathrm{ZrO}_{2}: \mathrm{Dy}^{3+}+x \mathrm{Li}^{+}$films were published in 2015 [67]. XRD measurements, as a function of the deposition temperature, indicated a meta-stable tetragonal crystalline structure of the zirconia. PL and CL features of the films were studied as a function of synthesis parameters such as the substrate temperature and the $\mathrm{Dy}^{3+}$ and $\mathrm{Li}^{+}$concentrations. All luminescent emission spectra showed peaks located at 485 (blue), 584 (yellow), 670 (red) and $760 \mathrm{~nm}$; which correspond to electronic transitions ${ }^{4} \mathrm{~F}_{9 / 2} \rightarrow{ }^{6} \mathrm{H}_{15 / 2},{ }^{4} \mathrm{~F}_{9 / 2} \rightarrow{ }^{6} \mathrm{H}_{13 / 2},{ }^{4} \mathrm{~F}_{9 / 2} \rightarrow{ }^{6} \mathrm{H}_{11 / 2}$, and ${ }^{4} \mathrm{~F}_{9 / 2} \rightarrow{ }^{6} \mathrm{H}_{9 / 2}$, of $\mathrm{Dy}^{3+}$, respectively. The $\mathrm{Li}^{+}$incorporation in the $\mathrm{ZrO}_{2}: \mathrm{Dy}^{3+}$ films produced an improvement in the intensity of the luminescent emission, presumably because it acts as a charge compensator and because it contributes to improving the crystalline structure of the host lattice. The CIE color coordinates $(0.3475,0.3609)$ of these films were found within the warm white light emission region. These spectroscopic characteristics allowed to propose this material for application in solid-state lighting (SSL), especially for white lighting emission applications. It is observed that, as the concentration of $\mathrm{Li}^{+}$ions increases, they come closer to the perfect white area of the CIE color coordinates $(0.3333,0.3333)$.

Moreover, in 2015 a work on $\mathrm{ZrO}_{2}, \mathrm{ZrO}_{2}: \mathrm{Dy}^{3+}$ and $\mathrm{ZrO}_{2}: \mathrm{Dy}^{3+}+\mathrm{Gd}^{3+}$ films was published [68]. The synthesis and the characterization conditions were carried out as described in Reference [67]. The relative concentrations of $\mathrm{Dy}^{3+}$ and $\mathrm{Gd}^{3+}$ ions were varied; the emission spectra of these films exhibited bands in the blue and yellow regions. The incorporation of $\mathrm{Gd}^{3+}$ ions in $\mathrm{ZrO}_{2}: \mathrm{Dy}^{3+}$ films generated a remarkable increase in the intensity of the luminescent emission (approximately 15 times). In principle, the host lattice absorbs the excitation energy which is transferred to the $\mathrm{Gd}^{3+}$ ions which in turn transfers it to the $\mathrm{Dy}^{3+}$ ions. The CIE chromaticity diagram exhibited a cold-white emission $\left(\mathrm{Dy}^{3+}-\mathrm{Gd}^{3+}\right.$ doped samples) and a warm-white emission ( $\mathrm{Dy}^{3+}$ doped samples), which shows the potential of these films for generating white light coatings for solid state lighting (SSL) applications.

The PL and structural properties of co-doped $\mathrm{ZrO}_{2}: \mathrm{Eu}^{3+}+\mathrm{Tb}^{3+}$ films, were also reported in 2015 [69]. The PL spectra showed the typical emission bands associated with the $\mathrm{Tb}^{3+}$ and Eu ${ }^{3+}$ ions, 
as well as a broad emission, peaked at $440 \mathrm{~nm}$ associated to radiative transitions within the $\mathrm{ZrO}_{2}$ host lattice. These films displayed multicolored emissions depending of the ratio $\mathrm{Eu}^{3+} / \mathrm{Tb}^{3+}$ and the excitation wavelength. The observed colors were: Blue (from the host lattice), green (from the $\mathrm{ZrO} 2: \mathrm{Tb}^{3+}$ films), red-orange (from the $\mathrm{ZrO}_{2}: \mathrm{Eu}^{3+}$ films), yellow (from the $\mathrm{ZrO}_{2}: \mathrm{Eu}^{3+}+\mathrm{Tb}^{3+}$ films, excited with $288 \mathrm{~nm}$ ) and bluish-white and yellowish white (from the $\mathrm{ZrO}_{2}: \mathrm{Eu}^{3+}+\mathrm{Tb}^{3+}$ films, excited with 368 or $380 \mathrm{~nm})$. The CIE coordinates of the double-doped $\mathrm{ZrO}_{2}: \mathrm{Tb}^{3+}\left(10\right.$ at.\%) $+\mathrm{Eu}^{3+}(5$ at.\%) films lie in the white light region of the chromaticity diagram and show good potential for lighting devices and photonic applications.

\section{2. $\mathrm{Al}_{2} \mathrm{O}_{3}$}

A pioneering work on luminescent $\mathrm{Al}_{2} \mathrm{O}_{3}: \mathrm{Tb}^{3+}$ films appeared in 1992 [70]. The films were deposited by the PSP technique on either plain or conductive oxide coated glass substrates at deposition temperatures in the range of $270-450{ }^{\circ} \mathrm{C}$. PL emission from these films showed well-defined peaks at 490 and $550 \mathrm{~nm}$, which were associated to the electronic transitions corresponding to $\mathrm{Tb}^{3+}$ ions. The relative emission intensity was strongly dependent on the type of substrate, the deposition temperature and the amount of $\mathrm{Tb}^{3+}$ ions incorporated in the films. Two years later, an investigation on $\mathrm{Al}_{2} \mathrm{O}_{3}: \mathrm{CeCl}_{3}$ films was published in 1994 [71]. PL spectra (excited with $300 \mathrm{~nm}$ light) showed a broad emission formed by two overlapping peaks at 365 and $395 \mathrm{~nm}$. It was suggested that these bands originate from the $5 \mathrm{~d}$ to $4 \mathrm{f}$ electronic energy levels of $\mathrm{Ce}$ in the $\mathrm{CeC}_{3}$ molecule. The PL emission intensity of these peaks was strongly dependent on the doping concentration and the substrate temperature. The films with greater intensity were those deposited at the lowest temperature, where there is a greater amount of $\mathrm{CeCl}_{3}$ incorporated in the films. As the temperature increases, the concentration of $\mathrm{CeCl}_{3}$ molecules decreases and so does the PL emission intensity-therefore, the presence of this molecule is essential for an optimal emission of blue light. Also, a quenching of the PL is observed for $\mathrm{CeCl}_{3}$ concentrations higher than 1 at.\%. Another research on $\mathrm{Al}_{2} \mathrm{O}_{3}: \mathrm{Eu}^{3+}$ films was published in 2000 [72]. These films were deposited by the USP technique at substrate temperatures from 300 to $540{ }^{\circ} \mathrm{C}$ and the $\mathrm{Eu}^{3+}$ doping concentration was varied. All films were amorphous in structure and the PL spectra were measured as a function of substrate temperature and doping concentration. The excitation spectrum showed an intense peak centered at $395 \mathrm{~nm}$. All the PL emission spectra (excited by $395 \mathrm{~nm}$ ) showed bands located at 587, 600, 612, and $648 \mathrm{~nm}$-typical of the electronic transitions in $\mathrm{Eu}^{3+}$ ions. It was observed a concentration quenching of the PL emission intensity at values of above 1.5 at.\% in the films. Thus, it was shown that $\mathrm{Al}_{2} \mathrm{O}_{3}$ is a suitable host lattice to support $\mathrm{RE}$ ions (such as $\mathrm{Eu}^{3+}$ ) to generate strong PL emissions.

In 2003, a new research in $\mathrm{Al}_{2} \mathrm{O}_{3}: \mathrm{Tb}^{3+}$ films was published [73]. In this case, the transparency of the films was up to $88 \%$ on the 400 to $700 \mathrm{~nm}$ range. These was possible because the use of organic source reactive for both aluminum and terbium (acetylacetonates) that were dissolved in dimethylformamide and sprayed, deposited at temperatures up to $600^{\circ} \mathrm{C}$. These films were mostly amorphous in the range of deposition temperatures studied with an average roughness of $14 \AA$ or less; which was perfect for the design and development of microdevices integrating this type of films. PL and CL spectra, studied as a function of the deposition parameters such as doping concentrations and substrate temperatures, were typical of the transitions among the electronic energy levels of the $\mathrm{Tb}^{3+}$ ions. Thus, from this work, it is clear that the use of acetylacetonates as precursors, generates the formation of high transmittance films with low roughness, as described in the dielectric section thin films, in contrast to those films synthesized from chlorides, nitrates or acetates (dissolved in water) which are, in general, very rough and opaque.

An energy transfer mechanism between $\mathrm{Ce}^{3+}$ and $\mathrm{Mn}^{2+}$ ions in alumina films was reported in 2005 [74]. Blue and red light emitting $\mathrm{Al}_{2} \mathrm{O}_{3}: \mathrm{Ce}^{3+}: \mathrm{Mn}^{2+}$ films, under ultraviolet light excitation, were investigated in this case. The blue emission is due to transitions from the excited state $5 \mathrm{~d}$ to the split ground state ${ }^{2} \mathrm{~F}$ of the $\mathrm{Ce}^{3+}$ ions. The usually weak $\mathrm{Mn}^{2+}$ ions red emission, attributed to intra $3 \mathrm{~d}$ transitions, was enhanced by an efficient energy transfer from the $\mathrm{Ce}^{3+}$ ions. The energy transfer 
mechanism was an electric dipole-quadrupole interaction with a quantum efficiency estimated to be near to $100 \%$, which makes these films interesting phosphors for the design of microdevices based on luminescent layers in flat-panel displays. Other studies on this type of amorphous $\mathrm{Al}_{2} \mathrm{O}_{3}: \mathrm{Ce}^{3+}: \mathrm{Mn}^{2+}$ films were also published $[75,76]$. However, in this case, the precursors were $\mathrm{AlCl}_{3}, \mathrm{CeCl}_{3}$ and $\mathrm{MnCl}_{2}$ dissolved in deionized water (Ce: 10 at.\%; Mn: 1, 3, 5, 7 and 10 at.\%), deposited at a substrate temperature of $300{ }^{\circ} \mathrm{C}$. The chemical composition and the profile distribution of the dopant ions across the films were determined by Rutherford backscattering (RBS). A homogeneous depth profile of both $\mathrm{Ce}^{3+}$ and $\mathrm{Mn}^{2+}$ ions was found within the films, and the overall measured quantities were as expected from the solution concentrations. Chlorine, which plays a significant role in luminescent properties, was detected in important quantities, something that was expected due to the low deposition temperatures used in this case. The red emission from manganese-doped samples was strongly enhanced with the co-doping with Ce due to the efficient energy transfer mechanism from $\mathrm{Ce}^{3+}$ to $\mathrm{Mn}^{2+}$ ions. From XPS analysis, it was determined that a considerable amount of Mn ions remains linked to chlorine, while $\mathrm{Ce}$ is mostly in an oxidized state.

In 2010, alumina was used to host three ions $\left(\mathrm{Tb}^{3+}, \mathrm{Ce}^{3+}\right.$, and $\left.\mathrm{Mn}^{2+}\right)$ to generate white light when excited by ultraviolet light [77]. These amorphous films were also deposited at $300{ }^{\circ} \mathrm{C}$. Sensitization of $\mathrm{Tb}^{3+}$ and $\mathrm{Mn}^{2+}$ ions by $\mathrm{Ce}^{3+}$ ions gave rise to blue, green and red luminescent emission when the film was excited with UV radiation. The overall efficiency of such energy transfer was about $85 \%$ upon excitation with $312 \mathrm{~nm}$ light. Energy transfer from $\mathrm{Ce}^{3+}$ to $\mathrm{Tb}^{3+}$ ions through an electric dipole-quadrupole interaction mechanism appeared to be more probable than the electric dipole-dipole one. A strong white light emission from the $\mathrm{Al}_{2} \mathrm{O}_{3}: \mathrm{Ce}^{3+}\left(1.3\right.$ at.\%): $\mathrm{Tb}^{3+}\left(0.2\right.$ at.\%): $\mathrm{Mn}^{2+}$ (0.3 at.\%) films under UV excitation was obtained. The high efficiency of energy transfer from $\mathrm{Ce}^{3+}$ to $\mathrm{Tb}^{3+}$ and $\mathrm{Mn}^{2+}$ ions, resulted in a cold white light emission $(x=0.30$ and $y=0.32)$. Thus, these films resulted interesting material for the design of efficient UV pumped phosphors for white light generation which could be integrated in light emitting microdevices.

Similarly, alumina co-doped with $\mathrm{Dy}^{3+}$ and $\mathrm{Ce}^{3+}$ ions was reported in 2011 [78]. The PL properties of these films were studied through excitation, emission spectra measurements and decay time spectroscopy. These films emitted a combination of blue and yellow colors through an efficient energy transfer $(77 \%)$ from $\mathrm{Ce}^{3+}$ to $\mathrm{Dy}^{3+}$ ions. It was inferred that such energy transfer was non-radiative, taking place between $\mathrm{Ce}^{3+}$ and $\mathrm{Dy}^{3+}$ clusters, through a short-range interaction mechanism. $\mathrm{Ce}^{3+}$ doped single films emitted in the violet-purplish-blue region; whereas co-doped films the presented a cold-white light emission. The PL properties of tri-doped $\mathrm{Al}_{2} \mathrm{O}_{3}: \mathrm{Ce}^{3+}: \mathrm{Dy}^{3+}: \mathrm{Mn}^{2+}$ films were published in 2012 [79]. Nonradiative energy transfer from $\mathrm{Ce}^{3+}$ to $\mathrm{Dy}^{3+}$ and $\mathrm{Mn}^{2+}$ was reported upon UV excitation at $278 \mathrm{~nm}$. From lifetime data, it was deducted that the energy transfer was nonradiative in nature. Simultaneous emission of all co-dopant ions in the blue, yellow and red regions, resulted in white light emission with CIE 1931 chromaticity coordinates, $x=0.34$ and $y=0.23$, with a color temperature of $4900 \mathrm{~K}$. Thin films as these might contribute to the development of materials that, pumped with AlGaN-based LEDs, could generate white light emission.

Also, in 2012, a study on the PL characteristics, under continuous and pulsed excitation of Eu-doped alumina films was reported [80]. It was determined that localized states in the undoped $\mathrm{Al}_{2} \mathrm{O}_{3}$ host lattice, excited with $250 \mathrm{~nm}$ radiation, emit a violet color (broad band centered at $415 \mathrm{~nm}$ ) associated to a radiative recombination process involving $\mathrm{F}$ centers. When $\mathrm{Eu}^{3+}$ ions were incorporated into these films, a charge transfer mechanism to these ions from the localized states seems to occur predominantly. The $\mathrm{Eu}^{3+}$ related emission, generated in this way, results intensified and luminescence decay time extended as compared to that obtained when the excitation is achieved through an inter-electronic energy level transition in the $\mathrm{Eu}^{3+}$ ion, excited by $395 \mathrm{~nm}$ radiation.

Subsequently, in 2013, a contribution on the white light emission from $\mathrm{Al}_{2} \mathrm{O}_{3}: \mathrm{Ce}^{3+}: \mathrm{Tb}^{3+}: \mathrm{Mn}^{2+}$ and $\mathrm{HfO}_{2}: \mathrm{Ce}^{3+}: \mathrm{Tb}^{3+}: \mathrm{Mn}^{2+}$ films was published [81]. These oxide films doped with $\mathrm{CeCl}_{3} / \mathrm{TbCl}_{3} / \mathrm{MnCl}_{2}$ were deposited at $300^{\circ} \mathrm{C}$. XRD measurements exhibited a very broadband typical of non-crystalline materials. Non-radiative energy transfer from $\mathrm{Ce}^{3+}$ to $\mathrm{Tb}^{3+}$ and $\mathrm{Mn}^{2+}$ ions is observed upon $\mathrm{UV}$ 
excitation at $280 \mathrm{~nm}$; the energy transfer could take place in $\mathrm{Ce}^{3+}-\mathrm{Tb}^{3+}$ and $\mathrm{Ce}^{3+}-\mathrm{Mn}^{2+}$ clusters through an electric dipole-quadrupole interaction mechanism. This energy transfer gives place to a simultaneous emission of the donor and acceptor ions in the blue, green, yellow and red regions, resulting white light emission. The chromaticity coordinates for $\mathrm{Al}_{2} \mathrm{O}_{3}: \mathrm{Ce}^{3+}: \mathrm{Tb}^{3+}: \mathrm{Mn}^{2+}$ films and color temperatures were: $(0.30,0.32)$ and $7300 \mathrm{~K}$ (cold-white color). The chromaticity coordinates for $\mathrm{HfO}_{2}: \mathrm{Ce}^{3+}: \mathrm{Tb}^{3+}: \mathrm{Mn}^{2+}$ films and color temperatures were $(0.32,0.37)$ and $6000 \mathrm{~K}$ (warm-white color).

Another study on PL emission (white emission) from single and double layered $\mathrm{Al}_{2} \mathrm{O}_{3}: \mathrm{Ce}^{3+}: \mathrm{Tb}^{3+}: \mathrm{Eu}^{3+}$ films was presented in 2013 [10]. These films were deposited using acetylacetonates (dissolved in dimethylformamide) as precursors. $\mathrm{Eu}^{3+}$ and $\mathrm{Tb}^{3+}$ doped films showed the typical emissions of these trivalent ions (red and green, respectively). Ce doped films showed two broad bands associated with the $5 \mathrm{~d}$ to $4 \mathrm{f}$ transitions of the $\mathrm{Ce}^{3+}$ ion, centered at $\sim 400$ and $510 \mathrm{~nm}$. As expected from films deposited with organic precursors, these films had low surface roughness (lower than $3 \mathrm{~nm}$ ) and thicknesses between 50 and $260 \mathrm{~nm}$. The double layer stacks involved first an $\mathrm{Eu}^{3+}$ doped film followed by a second $\mathrm{Ce}^{3+}-\mathrm{Tb}^{3+}$ co-doped layer. The films were transparent in the visible region, with an optical bandgap of approximately $5.63 \mathrm{eV}$. The PL of these stacks was an overlap of the emissions corresponding to all the dopants when excited with $300 \mathrm{~nm}$ light, resulting in an intense white light emission, which would be suitable for the design of electroluminescent microdevices.

The PL characteristics of $\mathrm{Eu}^{3+}$ doped alumina films co-doped with $\mathrm{Bi}^{3+}$ and $\mathrm{Li}^{+}$were published in 2015 [82]. In this case, the incorporation of $\mathrm{Bi}^{3+}$ and $\mathrm{Li}^{+}$ions as co-dopants in $\mathrm{Al}_{2} \mathrm{O}_{3}: \mathrm{Eu}^{3+}$ films and its effect on the luminescence characteristics of this material were described. Both $\mathrm{Bi}^{3+}$ and $\mathrm{Li}^{+}$ do not introduce new luminescence features but affect the luminescence intensity of the $\mathrm{Eu}^{3+}$ related emission spectra as well as the excitation spectra. The introduction of $\mathrm{Bi}^{3+}$ generates localized states in the aluminum oxide host that result in a quenching of the luminescence intensity, while $\mathrm{Li}^{+}$and $\mathrm{Bi}^{3+}$ co-doping increases the luminescence intensity of these films. It was found that the $\mathrm{Eu}^{3+}$ ions emission intensity in these films, when $\mathrm{Bi}^{3+}$ ions were added together with $\mathrm{Li}^{+}$, produce an increase of $62 \%$ in the emission intensity. It was suggested that the role of $\mathrm{Li}^{+}$co-doping was to redirect the energy paths back to the $\mathrm{Eu}^{3+}$ ions from the $\mathrm{Bi}^{3+}$ ions. Analysis of time decay measurements of the $\mathrm{Eu}^{3+}$ related emission in the amorphous alumina films indicated the presence of two type of sites in the short-range surroundings of the $\mathrm{Eu}^{3+}$ ions that could be correlated with those around this ion in $\alpha$ or $\gamma \mathrm{Al}_{2} \mathrm{O}_{3}$ crystalline phases.

\section{3. $\mathrm{HfO}_{2}$}

Luminescent $\mathrm{HfO}_{2}: \mathrm{Mn}^{2+}$ films (deposited by Ultrasonic Spray Pyrolysis technique) were reported for the first time, in 2004 [83]. The deposited films were amorphous at deposition temperatures up to $300{ }^{\circ} \mathrm{C}$; for higher temperatures a polycrystalline material was obtained with a monoclinic $\mathrm{HfO}_{2}$ phase. The cathodoluminescence $(C L)$ spectra showed blue-green and red bands associated with the electronic transitions ${ }^{4} \mathrm{~T}_{1}\left({ }^{4} \mathrm{G}\right) \rightarrow{ }^{6} \mathrm{~A}_{1}\left({ }^{6} \mathrm{~S}\right)$ of the $\mathrm{Mn}^{2+}$ ions. A dependence of the CL emissions, as a function of the doping concentration, substrate temperature and electron accelerating voltage was reported. It was determined that both amorphous and polycrystalline hafnium oxide make efficient host for $\mathrm{Mn}^{2+}$ ions, and that the relative content of chlorine in the processed films have an important role on the luminescent emission intensity of the studied materials.

USP deposited $\mathrm{HfO}_{2}: \mathrm{CeCl}_{3}$ films luminescent properties were published in 2007 [84]. These films were deposited from hafnium dichloride oxide and $\mathrm{CeCl}_{3}$ dissolved in deionized water $(18 \mathrm{M} \Omega / \mathrm{cm})$. The PL characteristics of the $\mathrm{HfO}_{2}: \mathrm{CeCl}_{3}$ films were studied as a function of doping concentrations and substrate temperature. XRD measurements showed the monoclinic phase of $\mathrm{HfO}_{2}$ for samples deposited at deposition temperatures higher than $400{ }^{\circ} \mathrm{C}$. These films showed a violet-blue PL emission that could easily be seen with the naked eye in normal room light. Also, PL emission and excitation spectra evidence the presence of two different $\mathrm{Ce}^{3+}$ centers in $\mathrm{HfO}_{2}$. A complete concentration quenching of the luminescence of one of the two centers is observed at high concentration of $\mathrm{CeCl}_{3}$ (15 at.\% in the start solution), which suggests a fast energy transfer from the high-energy to the low 
energy centers. Finally, it was confirmed that $\mathrm{HfO}_{2}$ is an adequate host matrix for rare earth ions as active centers to generate strong violet-blue PL emissions.

Also, in 2007, a work on PL properties of $\mathrm{HfO}_{2}: \mathrm{Tb}^{3+}$ films was published [85]. The PL properties of these films were studied as a function of deposition temperature and $\mathrm{Tb}^{3+}$ ions concentration. The films were deposited the USP technique from aqueous solution of Hafnium and Terbium chlorides. Results showed that crystalline structure of $\mathrm{HfO}_{2}: \mathrm{Tb}^{+3}$ films depends on the deposition temperature. PL excitation spectrum showed a wide band centered at $262 \mathrm{~nm}$ while the PL emission spectra showed bands centered at $488,542,584$ and $621 \mathrm{~nm}$, which correspond to the electronic transitions: ${ }^{5} \mathrm{D}_{4} \rightarrow{ }^{7} \mathrm{Fj}$ $(j=3,4,5,6)$ typical of trivalent terbium ions. The dominant emission intensity corresponds to the green color $(542 \mathrm{~nm})$, which depended on the terbium concentration incorporated in the host lattice; the optimum doping concentration was 5 at. $\% \mathrm{~Tb}^{+3}$ in the spraying solution.

The PL and CL characteristics of $\mathrm{HfO}_{2}: \mathrm{Sm}^{3+}$ films were published in 2008 [86]. These films were deposited by the USP technique on Corning glass substrates at deposition temperatures ranging from 300 to $550{ }^{\circ} \mathrm{C}$ using chlorides as precursor materials. Scanning electron microcopy (SEM) micrographs revealed rough surfaces morphology with spherical particles. The PL and CL spectra exhibited four main bands centered at 570, 610, 652 and $716 \mathrm{~nm}$, which are due to the well-known intra-4f transitions of the $\mathrm{Sm}^{+3}$ ions. It was found that the overall emission intensity rose as the deposition temperature was increased. Moreover, a concentration quenching of the emission intensity was observed for doping concentration higher than 0.7 at. \% as measured by EDS. These films showed good adherence to the substrate and a high deposition rate of up to $2 \mu \mathrm{m}$ per minute. In addition, The CL emission intensity was found to increase as the electron accelerating voltage was raised.

Also, in 2008, $\mathrm{HfO}_{2}$ films doped with $\mathrm{CeCl}_{3}$ and /or $\mathrm{MnCl}_{2}$ were deposited at $300{ }^{\circ} \mathrm{C}$ by the USP technique [87]. The XRD results revealed that the films were predominantly amorphous. $\mathrm{HfO}_{2}$ : $\mathrm{CeCl}_{3}$ showed a violet-blue emission. The weak green-red emissions of $\mathrm{Mn}^{2+}$ ions was enhanced through an efficient energy transfer from $\mathrm{Ce}^{3+}$ to $\mathrm{Mn}^{2+}$ ions in the co-doped films. Spectroscopic data indicated that this energy transfer was nonradiative in nature and it could occur in $\mathrm{Ce}^{3+}$ and $\mathrm{Mn}^{2+}$ clusters through a short-range interaction mechanism. The efficiency of this energy transfer increases with the $\mathrm{Mn}^{2+}$ ion concentration, so that an efficiency of about $78 \%$ is achieved for a 5 at. $\%$ of $\mathrm{MnCl}_{2}$ concentration. The $\mathrm{HfO}_{2}: \mathrm{CeCl}_{3}: \mathrm{MnCl}_{2}$ films are interesting phosphors for the design of luminescent layers emitting simultaneously in the three primary colors: Violet-blue, green and red.

The $\mathrm{HfO}_{2}$ host lattice was also used to house, simultaneously, ions such as $\mathrm{Ce}^{3+}, \mathrm{Tb}^{3+}$ and $\mathrm{Mn}^{2+}$ to generate cold white light [88]. These films were either doubly doped with $\mathrm{CeCl}_{3}$ and $\mathrm{TbCl}_{3}$ or tri-doped with $\mathrm{CeCl}_{3}, \mathrm{TbCl}_{3}$, and $\mathrm{MnCl}_{2}$ and deposited at $300{ }^{\circ} \mathrm{C}$. In the doubly doped films, energy transfer from $\mathrm{Ce}^{3+}$ to $\mathrm{Tb}^{3+}$ ions could take place in $\mathrm{Ce}^{3+}-\mathrm{Tb}^{3+}$ clusters through an electric dipole-quadrupole interaction; the efficiency of this transfer was about $81 \%$ upon excitation with $270 \mathrm{~nm}$ light. In the triply doped films, both $\mathrm{Tb}^{3+}$ and $\mathrm{Mn}^{2+}$ ions, can be sensitized by $\mathrm{Ce}^{3+}$ ions. The efficiency of energy transfer from $\mathrm{Ce}^{3+}$ to $\mathrm{Tb}^{3+}$ and $\mathrm{Mn}^{2+}$ ions was enhanced by increasing the $\mathrm{Mn}^{2+}$ concentration, up to about $76 \%$ for the films with the highest $\mathrm{Mn}^{2+}$ ions content (1.6 at.\%). The simultaneous emission of these ions under UV excitation resulted in white light luminescence.

The PL and TL properties of $\mathrm{HfO}_{2}$ films were investigated [89], these films were synthesized from hafnium chloride as raw material in deionized water as solvent and were deposited at temperatures from 300 to $600{ }^{\circ} \mathrm{C}$. SEM images showed that the film's surface resulted very rough with semi-spherical promontories. UV irradiation was used in order to perform the thermo-luminescent (TL) characterization of these films; the $240 \mathrm{~nm}$ wavelength irradiation induced the best response. The PL spectra showed emission bands, centered at 425, 512 and $650 \mathrm{~nm}$, associated to impurities such as chlorine and/or structural defects. As the substrate temperature was raised, a higher intensity of the band centered at $425 \mathrm{~nm}$ was observed. The TL experimental results showed that $\mathrm{HfO}_{2}$ films could be useful in UV radiation dosimetry applications, using the TL method mainly in the interval of 200-400 nm; indicating an advantage over other ultraviolet dosimeters currently used. 
An investigation on the luminescent properties of $\mathrm{HfO}_{2}$ films co-doped with $\mathrm{Ce}^{3+}$ and several concentrations of $\mathrm{Dy}^{3+}$ was presented in 2011 [90]. The deposition temperature was $300{ }^{\circ} \mathrm{C}$. PL emissions from $\mathrm{Dy}^{3+}$ ions centered at $480 \mathrm{~nm}$ (blue) and $575 \mathrm{~nm}$ (yellow) associated with the ${ }^{4} \mathrm{~F}_{9 / 2} \rightarrow{ }^{6} \mathrm{H}_{15 / 2}$ and ${ }^{4} \mathrm{~F}_{9 / 2} \rightarrow{ }^{6} \mathrm{H}_{13 / 2}$ electronic transitions, respectively, were observed upon UV $(280 \mathrm{~nm})$ excitation via a non-radiative energy transfer from $\mathrm{Ce}^{3+}$ to $\mathrm{Dy}^{3+}$ ions. Such energy transfer via an electric dipole-quadrupole interaction appeared to be the most probable transfer mechanism. The efficiency of this transfer increases up to $86 \pm 3 \%$ for the film with the highest $\mathrm{Dy}^{3+}$ content (1.9 \pm 0.1 at.\% as measured by EDS). The possibility of achieving the coordinates of ideal white light with increasing the concentration of $\mathrm{Dy}^{3+}$ ions was demonstrated.

The PL, CL, and TL characteristics of $\mathrm{HfO}_{2}: \mathrm{Dy}^{3+}$ films were also reported in 2014 [91]. The films were deposited at temperatures ranging from 300 to $600{ }^{\circ} \mathrm{C}$, using chlorides as precursor reagents. XRD diffraction studies showed the presence of $\mathrm{HfO}_{2}$ monoclinic phase in the films deposited at substrate temperatures greater than $400{ }^{\circ} \mathrm{C}$. The surface morphology of films showed a veins shaped microstructure at low deposition temperatures, while at higher temperatures the formation of spherical particles was observed. The PL (excitation $=248 \mathrm{~nm}$ ) and CL spectra of the doped films showed the highest emission in the band centered at $575 \mathrm{~nm}$ (yellow) corresponding to the transitions ${ }^{4} \mathrm{~F}_{9 / 2} \rightarrow{ }^{6} \mathrm{H}_{13 / 2}$, which is a typical transition of $\mathrm{Dy}^{3+}$ ions. Regarding the TL behavior, the glow curve of $\mathrm{HfO}_{2}: \mathrm{Dy}^{+3}$ films exhibited spectrum with one broad band centered at about $150{ }^{\circ} \mathrm{C}$. The highest intensity TL response was observed on the films deposited at $500{ }^{\circ} \mathrm{C}$. A concentration quenching was observed and the optimum $\mathrm{DyCl}_{3}$ concentration was 1 at.\% in the initial solution. It was also determined that substrate temperature for the sample with maximum PL emission intensity was $600{ }^{\circ} \mathrm{C}$. The PL (yellowish-white emission) is intense since it can be observed by the naked eyes with normal ambient illumination.

$\mathrm{HfO}_{2}$ films co-doped with $\mathrm{Tb}^{3+}$ or $\mathrm{Eu}^{3+}$ ions using acetylacetonates as precursors, were studied [92]. The films presented transmittance values in the visible region $\cong 90 \%$ and surface roughness less than $3.9 \mathrm{~nm}$. These films were polycrystalline with a monoclinic phase for films deposited at substrate temperatures higher than $500^{\circ} \mathrm{C}$. The luminescent emissions (PL and CL) were typical of $\mathrm{Tb}^{3+}$ and $\mathrm{Eu}^{3+}$ ions with a luminescence concentration quenching observed for both $\mathrm{Tb}^{3+}$ and $\mathrm{Eu}^{3+}$ ions at 5 and 10 at.\%, respectively. The peak PL and CL emission intensities for single doped films were observed for $\mathrm{HfO}_{2}: \mathrm{Tb}^{3+}$ (5 at.\%) and $\mathrm{HfO}_{2}: \mathrm{Eu}^{3+}$ (10 at.\%) films deposited at $500{ }^{\circ} \mathrm{C}$. The refractive index observed in these films was between 1.97 and 2.04 and an optical band gap of $5.4 \mathrm{eV}$. The PL decay time measurements was measured on some $\mathrm{HfO}_{2}: \mathrm{Tb}^{3+}, \mathrm{Eu}^{3+}$ samples. QE around

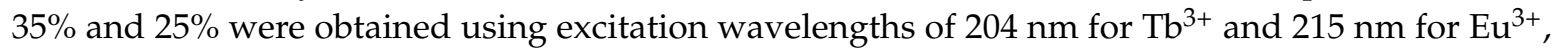
respectively. $\mathrm{HfO}_{2}$ films co-doped with $\mathrm{Tb}^{3+}$ and $\mathrm{Eu}^{3+}$ ions were synthesized at substrate temperatures from 400 to $600{ }^{\circ} \mathrm{C}$ using chlorides as reactive source materials [93]. These films became polycrystalline at $600{ }^{\circ} \mathrm{C}$ exhibiting the $\mathrm{HfO}_{2}$ monoclinic phase. Tuning by the means of the excitation wavelength and the relative concentration of the co-dopants, PL spectra with several shades, from blue to yellow (including white light) were obtained due to the combined emissions of $\mathrm{Tb}^{3+}$ (green), $\mathrm{Eu}^{3+}$ (red) ions and the host lattice $\left(\mathrm{HfO}_{2}\right)$ violet-blue emission. The best white light emission $(x=0.3343, y=0.3406)$ was obtained with $382 \mathrm{~nm}$ excitation light and 1.35 and 0.88 at.\% of $\mathrm{Tb}$ and Eu in the films, respectively. The CL emission spectra for these films also showed emissions from green to red (including yellow, orange, and other intermediate emissions depending on the relative content of $\mathrm{Tb}$ and Eu in the film). Quantum efficiency values between $47 \%$ and $78 \%$ were obtained for these films, depending on the excitation wavelength and co-doping concentrations.

\section{4. $\mathrm{Y}_{2} \mathrm{O}_{3}$}

The first publication on $\mathrm{Y}_{2} \mathrm{O}_{3}: \mathrm{Eu}^{3+}$ particles (synthesized by the spray pyrolysis process) was registered in the year 2000 [94]. These particles were prepared from high solution concentrations which had a more hollow and porous structure than those prepared from low-concentration solutions. The PL spectra showed a prominent peak at $612 \mathrm{~nm}$ (pure red color). The colloidal seed-assisted 
spray pyrolysis introduced in this paper was found to be applicable to the control of morphology of phosphor particles when the stock solution concentration was high. For the colloidal seed-assisted spray pyrolysis, the stable colloidal solution should be used for homogeneity of phase and morphology of the phosphor particles. The colloidal solution of $Y$ and Gd hydroxy carbonate sol obtained by the liquid phase reaction method, using urea, was appropriate for the preparation of $\mathrm{Y}_{2} \mathrm{O}_{3}$ : $\mathrm{Eu}^{3+}$ particles of filled and non-porous structure at high concentration of the precursor solution. The fine particles size prepared from the colloidal solution compared to those of the aqueous solution also revealed that the particles prepared from colloidal solution are much less hollow.

CL of USP deposited $\mathrm{Y}_{2} \mathrm{O}_{3}$ thin films doped separately with $\mathrm{Eu}^{3+}, \mathrm{Tb}^{3+}$ and $\mathrm{Tm}^{3+}$ were reported in 2001 [95]. CL spectra for films doped with $\mathrm{Eu}^{3+}, \mathrm{Tb}^{3+}$ or $\mathrm{Tm}^{3+}$ ions presented red, green, and blue light emissions, respectively. The blue emission of $\mathrm{Y}_{2} \mathrm{O}_{3}: \mathrm{Tm}^{3+}$ films had dominant peak at $476 \mathrm{~nm}$. The $\mathrm{CL}$ intensity of these films depended strongly on annealing conditions and thulium doping concentration, presenting a maximum luminance of $30.4 \mathrm{~cd} / \mathrm{m}^{2}$. For the $\mathrm{Eu}^{3+}$-doped films, a luminance of $255 \mathrm{~cd} / \mathrm{m}^{2}$ was obtained with a dominant peak centered at $604 \mathrm{~nm}$. The luminance for the $\mathrm{Tb}^{3+}$-doped film was $72 \mathrm{~cd} / \mathrm{m}^{2}$ with a dominant peak at $547 \mathrm{~nm}$.

The role of $\mathrm{LiCl}$ added as flux on the luminescence properties of USP synthesized $\mathrm{Y}_{2} \mathrm{O}_{3}: \mathrm{Eu}^{3+}$ phosphors was investigated in 2002 [96]. The maximum PL intensity was obtained for phosphors prepared at $1300{ }^{\circ} \mathrm{C}$ from solution with $\mathrm{LiCl}$ flux, their intensity was $50 \%$ higher than that of phosphors prepared from solution without flux. The PL intensities of phosphors prepared at 700 and $900{ }^{\circ} \mathrm{C}$ from flux solution were $200 \%$ and $134 \%$ of those phosphors processed from solutions without flux at the same synthesis temperatures. $\mathrm{LiCl}$ flux played the role of enhancing the luminescence of $\mathrm{Eu}^{3+}$ ions into $\mathrm{Y}_{2} \mathrm{O}_{3}$ host lattice by reducing defects in the phosphor particles.

Furthermore, in 2002, a study on spherical particles of $\mathrm{Y}_{2} \mathrm{O}_{3}: \mathrm{Eu}^{3+}$ was published [97]. $\mathrm{Y}_{2} \mathrm{O}_{3}: \mathrm{Eu}^{3+}$ luminescent particles of spherical shape, filled morphology, and high brightness were prepared by combination of colloidal seed assisted spray pyrolysis and flux-added spray pyrolysis. $\mathrm{Y}_{2} \mathrm{O}_{3}: \mathrm{Eu}^{3+}$ particles processed from $\mathrm{Y}$ colloidal solution with 5 at. $\% \mathrm{LiCl} / \mathrm{KCl}$ flux showed completely spherical shape, filled morphology, high crystallinity, and significantly improved PL emission intensity, which was $30 \%$ higher than that of particles prepared by general spray pyrolysis.

Another study on $\mathrm{Y}_{2} \mathrm{O}_{3}: \mathrm{Eu}^{3+}$ powders was published in 2005 [98]. These powders were synthesized by spray pyrolysis process and annealed at several temperatures, in the range $900-1400{ }^{\circ} \mathrm{C}$, to achieve crystallized luminescent materials. The microstructure and macrostructure of these powders were investigated by high resolution SEM images and XRD measurements. The luminescent properties were measured under VUV excitation $(254 \mathrm{~nm})$. The results of this work allowed to understand the influence of the phosphors' microstructure on PL characteristics. The spray pyrolysis powder PL efficiencies excited at $254 \mathrm{~nm}$ were lower than that of the commercial phosphor but under a $600 \mathrm{mbar}$ $\mathrm{Ne}-$ Xe plasma excitation (this measurement provides a characteristic close to the working conditions in plasma display panels); the powder the brightness was equal that of the commercial phosphor. The results allowed differentiating the microstructure and macrostructure influence on luminescence. Eventually, a suitable phosphor powder for plasma display panels less dense than the commercial one has been prepared by spray pyrolysis.

A control of the morphology of $\mathrm{Y}_{2} \mathrm{O}_{3}: \mathrm{Eu}^{3+}$ phosphor particles in the spray pyrolysis process was attempted by using citric acid and polyethylene glycol (PEG) as additives in the spray precursors [99]. Three different morphologies of phosphor particles were obtained: Smooth spheres, rods, and flakes (with the presence of PEG with different molecular weights or without the presence of PEG, respectively). It was shown that the spherical $\mathrm{Y}_{2} \mathrm{O}_{3}: \mathrm{Eu}^{3+}$ particles, obtained through a two-step spray pyrolysis process, had higher PL intensity than those with other morphologies.

In a similar work to the previous ones, also published in 2005, it was demonstrated that the densified particles of $\mathrm{Y}_{2} \mathrm{O}_{3}: \mathrm{Eu}^{3+}$ remarkably improved the intensity of PL emissions [100]. High luminous $\mathrm{Y}_{2} \mathrm{O}_{3}$ : $\mathrm{Eu}^{3+}$ phosphor particles with spherical shape were synthesized by Spray Pyrolysis technique. A simple but effective preparation strategy for enhancing the PL intensity 
of these particles was implemented. The yttrium nitrate solution was modified using an organic additive, then non-hollow particles were reached, but they were very porous, and the PL intensity was not improved. To solve this disadvantage, a drying control chemical additive (DCCA) was used as a secondary additive. It was found that the surface area was greatly reduced, and the crystallite size was increased by the use of DCCA. As a consequence, densified $\mathrm{Y}_{2} \mathrm{O}_{3}: \mathrm{Eu}^{3+}$ particles showed great improvement in their PL emission intensity.

The luminescent characteristics of $\mathrm{Y}_{2} \mathrm{O}_{3}: \mathrm{Eu}^{3+}$ (5 and 10 at.\%) submicron particles, synthesized from the pure nitrate solutions at $900{ }^{\circ} \mathrm{C}$, was also reported in 2010 [101]. The synthesis conditions (gradual increase of temperature within triple zone reactor and extended residence time) assured formation of spherical, dense, non-agglomerated particles with a crystallite size about $20 \mathrm{~nm}$ with a cubic $\mathrm{Y}_{2} \mathrm{O}_{3}$ crystalline phase. PL emission spectra were studied under excitation with $393 \mathrm{~nm}$ and together with the decay lifetimes for $\mathrm{Eu}^{3+}$ ion ${ }^{5} \mathrm{D}_{0}$ and ${ }^{5} \mathrm{D}_{1}$ levels revealed the effect of nanocrystalline nature on the luminescent properties of the powders. The PL emission spectra showed typical $\mathrm{Eu}^{3+5} \mathrm{D}_{0} \rightarrow{ }^{7} \mathrm{~F}_{\mathrm{i}}(\mathrm{i}=0,1,2,3,4)$ electronic transitions with dominant red emission at $611 \mathrm{~nm}$, while the lifetime measurements revealed the quenching effect with the rise of dopant concentration and its more consistent distribution into host lattice due to the thermal treatment. The nanostructured $\mathrm{Y}_{2} \mathrm{O}_{3}: \mathrm{Eu}^{3+}$ phosphors possess favorable morphological properties for applications as red phosphor in optoelectronic microdevices, for example for luminescent displays.

$\mathrm{Y}_{2} \mathrm{O}_{3}$ powders doped with $\mathrm{Yb}^{3+}$ and co-doped either with $\mathrm{Tm}^{3+}$ or $\mathrm{Ho}^{3+}$ were synthesized and reported in 2012 [102]. These powders were processed at $900{ }^{\circ} \mathrm{C}$ using $0.1 \mathrm{M}$ nitrates precursor solution and a cubic structure with space group Ia-3 was confirmed for all samples. Spherical particles with average size about $400 \mathrm{~nm}$ were generated with certain degree of porosity which alters their morphology during additional thermal treatment. The up-conversion emission spectra after excitation with $978 \mathrm{~nm}$, as well as emission lifetimes and up-converted emission intensity dependence on excitation power were investigated. Dominant green $\left({ }^{5} \mathrm{~F}_{4},{ }^{5} \mathrm{~S}_{2} \rightarrow{ }^{5} \mathrm{I}_{8}\right)$ and blue $\left({ }^{1} \mathrm{G}_{4} \rightarrow{ }^{3} \mathrm{H}_{6}\right)$ emissions were found for $\mathrm{Ho}^{3+}$ and $\mathrm{Tm}^{3+}$ samples, respectively. The enhanced emission intensities and lifetime in thermally treated samples were correlated with morphological and structural changes observed.

The enhancement of the PL emission intensity from $\mathrm{Y}_{2} \mathrm{O}_{3}: \mathrm{Er}^{3+}$ thin films with $\mathrm{Li}^{+}$as co-dopant was published in 2013 [103]. These films were deposited using $0.03 \mathrm{M}$ of yttrium acetylacetonate, dissolved in $\mathrm{N}, \mathrm{N}$-dimethylformamide. The doping of the films with Er was achieved by adding erbium (III) acetate in the solution at $1.5 \%$ in relation to the $\mathrm{Y}$ content. The co-doping with $\mathrm{Li}$ was achieved adding lithium acetylacetonate to the spraying solution; the Li contents studied were $0,0.5,1,2,3$, 3.5 , and 4 at.\% in relation to the $\mathrm{Y}$ content. The films were deposited at $500{ }^{\circ} \mathrm{C}$ on $\left(\begin{array}{lll}1 & 0 & 0\end{array}\right)$ silicon wafers. These films were polycrystalline with a pure $\mathrm{Y}_{2} \mathrm{O}_{3}$ cubic phase. The typical $\mathrm{Er}^{3+}$ related emission spectra showed an intensity increase by a factor of $\sim 4-5$ times with the addition of $2 \%$ of $\mathrm{Li}^{+}$. This behavior is attributed to the distortion of the local crystalline field induced by the incorporation of $\mathrm{Li}^{+}$ions. The addition of $\mathrm{Li}^{+}$reduces the intensity of the diffraction peaks after $1 \%$, and shifts the main diffraction peak toward large angles for $\mathrm{Li}^{+}$doping less than $3 \%$. The distortion of the crystalline field leads to an increment of the efficiency of intra- $4 \mathrm{f}$ transitions by permitting the otherwise parity forbidding transitions and reducing alternative nonradiative processes. These results showed that the low-cost ultrasonic spray pyrolysis technique was a simple way to obtain rare earth doped metallic oxide films co-doped with $\mathrm{Li}^{+}$ions as a strategy to improve their PL emission intensity.

The enhancement of the PL emission from $\mathrm{Y}_{2} \mathrm{O}_{3}: \mathrm{Er}^{3+}$ films, with the incorporation of $\mathrm{Li}^{+}$ions, was reported in 2014 [104] for both visible and IR characteristic emissions of $\mathrm{Er}^{3+}$ ions. The presence of $\mathrm{Li}^{+}$ions in the USP deposited films was inferred from Fourier transform infrared (FTIR) spectroscopy and also measured by Ion Beam Analysis (EBS), in which the high energies $\alpha$ particle yield from the ${ }^{7} \mathrm{Li}(\mathrm{p}, \alpha)^{4} \mathrm{He}$ nuclear reaction was used to determine the content of $\mathrm{Li}^{+}$inside the films. The average content of $\mathrm{Li}^{+}$inside the films, as determined by EBS, increases from 0 up to $18.5 \mathrm{at} \%$ for un-doped to 4 at. $\% \mathrm{Li}^{+}$co-doped samples. The $\mathrm{Li}-\mathrm{C}-\mathrm{O}$ absorption band in the IR region was directly proportional to the $\mathrm{Li}^{+}$content inside the films and a calibration curve was generated with the EBS analysis. In a 
related work [105], the effect of $\mathrm{Li}^{+}$co-doping on PL time decay characteristics of $\mathrm{Y}_{2} \mathrm{O}_{3}: \mathrm{Er}^{3+}$ was reported for films deposited at $500{ }^{\circ} \mathrm{C}$. The $\mathrm{Er}^{3+}$ content, in this case, was fixed at 1.5 at. $\%$ while the $\mathrm{Li}^{+}$ content in the spraying solution was varied from 1 to 4 at.\% in relation to $\mathrm{Y}^{3+}$ content. The addition of $\mathrm{Li}^{+}$content up to 2 at.\%, besides resulting in an increase of the luminescence emission intensity, modified the luminescence time decay behavior as well. A simple model in which charge transfer from localized centers to the $\mathrm{Er}^{3+}$ ions was proposed to describe the temporal evolution of the PL emission. The introduction of $\mathrm{Li}^{+}$ions in $\mathrm{Y}_{2} \mathrm{O}_{3}: \mathrm{Er}^{3+}$ had an impact on the charge transfer $(\mathrm{CT})$ process and on the total number of $\mathrm{Er}^{3+}$ ions contributing to the PL emission. The PL time decay characteristics of $\mathrm{Y}_{2} \mathrm{O}_{3}: \mathrm{Er}^{3+}$ films under $207 \mathrm{~nm}$ or $414 \mathrm{~nm}$ excitation light were analyzed with a simple model in which, in addition to the radiative recombination sites associated with $\mathrm{Er}^{3+}$ ions, a CT process from localized states was considered.

Luminescent and structural characteristics of $\mathrm{Y}_{2} \mathrm{O}_{3}: \mathrm{Tb}^{3+}$ thin films deposited from $\beta$-diketonates as precursors on c-Si substrates, at temperatures in the $400-550{ }^{\circ} \mathrm{C}$ range, were reported in 2014 [106]. The PL and CL spectra intensity depended strongly on substrate temperature, the thickness of the films and the $\mathrm{Tb}^{3+}$ doping concentration. $\mathrm{Y}_{2} \mathrm{O}_{3}: \mathrm{Tb}^{3+}$ thin films exhibited one main band centered at $547 \mathrm{~nm}$ due to the ${ }^{5} \mathrm{D}_{4} \rightarrow{ }^{7} \mathrm{~F}_{5}$ electronic transition of the $\mathrm{Tb}^{3+}$ ion. A concentration quenching of the luminescence intensity was observed. At high temperatures the cubic crystalline phase of $\mathrm{Y}_{2} \mathrm{O}_{3}$ was observed as well as a reduction of organic residues. Also, at elevated temperatures, a low average surface roughness was obtained in the films with a high transmittance in the visible region.

$\mathrm{PL}$ and CL from $\mathrm{Y}_{2} \mathrm{O}_{3}$ doped with $\mathrm{Tb}^{3+}$ and $\mathrm{Eu}^{3+}$ ions films results were published in 2015 [107]. The deposition conditions were similar to those of the work described above. The optical and structural characterization of these films was carried out as a function of substrate temperature and $\mathrm{Tb}^{3+}$ and $\mathrm{Eu}^{3+}$ concentrations. Films deposited above $450{ }^{\circ} \mathrm{C}$ exhibited the typical PL bands associated with either $\mathrm{Tb}^{3+}$ or $\mathrm{Eu}^{3+}$ intra electronic energy levels transitions. The most intense PL and CL emissions were found for dopant concentration of 10 at. $\%$ for $\mathrm{Tb}^{3+}$ and at 8 at. $\%$ for $\mathrm{Eu}^{3+}$ ions in spraying solution. Higher substrate temperatures improved the crystallinity of $\mathrm{Y}_{2} \mathrm{O}_{3}$ films, and showed a low average surface roughness ( $62 \AA$ for $\mathrm{Y}_{2} \mathrm{O}_{3}: \mathrm{Tb}^{3+}$, and $25 \AA$ for $\mathrm{Y}_{2} \mathrm{O}_{3}: \mathrm{Eu}^{3+}$ thin films). The films reported in this work were dense, and showed high refraction index (1.81), as well as a high optical transmittance in the UV-Vis range (about $90 \%$ ) of the electromagnetic spectrum. These results suggest the possibility of applying those films in electroluminescent microdevices.

Recently, in 2017, an investigation on luminescent (PL and TL) $\mathrm{Y}_{2} \mathrm{O}_{3}: \mathrm{Sm}^{3+}$, Li nanostructured thin films was presented [108]. XRD measurements confirmed the cubic structure of $\mathrm{Y}_{2} \mathrm{O}_{3}$ thin films. $\mathrm{Li}$ ions were successfully incorporated into the $\mathrm{Y}_{2} \mathrm{O}_{3}$ host lattice and it served as a sensitizer for better crystallization. The crystallites sizes are found to be $\sim 50 \mathrm{~nm}$. Surface morphology appeared as carved sculptures of particles with agglomeration. Optical absorption spectrum exhibited a prominent absorption peak at $270 \mathrm{~nm}$ and the corresponding energy gap was found to be $\sim 5.53 \mathrm{eV}$. A broad PL emission was observed in the range 560-690 nm with peaks at 595, 608 and $622 \mathrm{~nm}$ corresponding to characteristic electronic transitions in the $\mathrm{Sm}^{3+}$ ions. These films were irradiated with $\gamma$-rays in a dose range 187-563 Gy; TL glow curve is deconvoluted into three peaks with temperature maxima at 400,460 and $580 \mathrm{~K}$. The activation energy and frequency factor of these TL glows were found to be in the order of $\sim 0.58 \mathrm{eV}$ and $\sim 10^{6} \mathrm{~s}^{-1}$, respectively. Trap depths for the three luminescent centers were calculated and dose response was found to be linear in the range of 422-469 Gy.

\section{5. $\mathrm{ZnO}$}

Zinc oxide $(\mathrm{ZnO})$ is one of the most studied materials due to the various areas in which it is used. This material in the form of films and powders has also been frequently synthesized by the spray pyrolysis technique. One of the first studies on luminescent films deposited by the PSP technique of this material was on $\mathrm{ZnO}: \mathrm{TbCl}_{3}$ films published in 1987 [8]. Both intrinsic and $\mathrm{ZnO}: \mathrm{TbCl}_{3}$ films were deposited at atmospheric pressure, using air as the carrier gas. The substrate temperature during deposition was varied from 270 to $400{ }^{\circ} \mathrm{C}$. The solution flow rate was changed in the range of 
$4-16 \mathrm{~cm}^{3} / \mathrm{min}$ and the carrier gas flow rate was kept constant throughout the deposition process at $10 \mathrm{I} / \mathrm{min}$; the deposition time was 10 minutes in all cases and the $\mathrm{TbCl}_{3}$ concentration was 10 at.\%. These films were polycrystalline with a hexagonal wurtzite structure. The PL spectra from un-doped films showed a peak centered at $510 \mathrm{~nm}$ [109], while $\mathrm{ZnO}: \mathrm{TbCl}_{3}$ films showed a peak at $550 \mathrm{~nm}$ associated to electronic transitions in the $\mathrm{Tb}^{3+}$ ions. Later in a follow up study about these films [110] it was reported that the light emission of the $\mathrm{ZnO}: \mathrm{TbCl}_{3}$ decreased with time of exposure of the sample to the excitation radiation. The phenomenon was interpreted in terms of a simple model in which a competitive process of hole trapping and photo-detrapping occurred at a radiative recombination center generated by the presence of $\mathrm{TbCl}_{3}$.

The luminescence of undoped $\mathrm{ZnO}$ films, deposited from zinc nitrate solution, was also published in 1998 [111]. The films had a polycrystalline hexagonal wurtzite type structure with no preferred orientation. Green and orange PL (excited by $320 \mathrm{~nm}$ light) with emission intensity strongly dependent on the deposition and annealing temperatures was reported. The best green (broad band peaked at $510 \mathrm{~nm}$ ) luminescent films had a porous structure while orange (band peaked at $640 \mathrm{~nm}$ ) films consisted of close-packed grains with diameters of up to more than 1 micrometer. Green and orange PL bands resulted from oxygen-poor and oxygen-rich states, respectively, in $\mathrm{ZnO}$. In the case of the green films, the vacancies did not appear to penetrate deeply into the crystallites.

The effect of $\mathrm{Li}$ ions incorporation on the luminescence of $\mathrm{ZnO}$ films was reported in 1990 [112]. The spraying solution was $0.1 \mathrm{M}$ zinc acetate in isopropyl alcohol and deionized water mixed in equal proportions. Lithium chloride was added to the spraying solution at a concentration of 10 at.\%. All deposited films exhibited a hexagonal polycrystalline structure. The optical transmission depended on the deposition temperatures $\left(\mathrm{Ts}=340-330^{\circ} \mathrm{C}\right.$ ) which showed an absorption edge shifting to longer wavelengths with higher Ts. The PL spectra of samples deposited at low Ts showed two emissions located at $420 \mathrm{~nm}$ and $500 \mathrm{~nm}$, associated with blue emission from the Pyrex glass substrate and the blue green emission typical of un-doped zinc oxide, respectively. Films deposited at high Ts showed an emission peak centered at $555 \mathrm{~nm}$ apparently associated with the localized states generated by incorporation of $\mathrm{Li}$ ions in the $\mathrm{ZnO}$ films.

The photoluminescence from PSP deposited indium doped ZnO films was reported in 1992 [113]. This study was carried out as a function of the substrate temperature and solution flow rate. Deposition solution was $0.1 \mathrm{M}$ zinc acetate in three parts of isopropyl alcohol mixed with one part of deionized water. Indium doping was achieved by adding $\mathrm{InCl}_{3}$ to the spraying solution in a concentration of 2 at.\%. The substrate temperature was varied from 260 to $320^{\circ} \mathrm{C}$. These films were polycrystalline with a hexagonal crystalline structure; high solution flow rates resulted in larger disorder on the orientation of the polycrystallites. The PL spectra from films deposited at low substrate temperature or with high solution flow rate showed a broad peak centered at $530 \mathrm{~nm}$ which was associated with $\left(\operatorname{In}_{\mathrm{Zn}} \mathrm{Vz}\right)$-luminescent centers.

The green photoluminescence efficiency and free-carrier density in $\mathrm{ZnO}$ phosphor powders were investigated in 1997 [114]. An aqueous zinc nitrate solution (10 at.\% Zn) was utilized in the synthesis of all powders at processing temperatures from 700 to $900{ }^{\circ} \mathrm{C}$. Electron paramagnetic resonance, optical absorption, and photoluminescence spectroscopy were combined to characterize $\mathrm{ZnO}$ powders. Green PL emission was generated and a good correlation between the $510 \mathrm{~nm}$ green emissions with the density of paramagnetic isolated oxygen vacancies was observed. Also, both quantities increase with free-carrier concentration $\mathrm{n}_{\mathrm{e}}$, as long as $\mathrm{n}_{\mathrm{e}}<1.4 \times 10^{18} \mathrm{~cm}^{-3}$. At higher free-carrier concentrations, both quantities decrease. A model is proposed involving the isolated oxygen vacancy as the luminescence center. It was also shown that a free-carrier depletion layer, which forms at the surface of the powder particles, and the overall free-carrier concentration of the particles have a large impact on the green emission intensity of the $\mathrm{ZnO}$ powder.

PL from $\mathrm{ZnO}$ and $\mathrm{ZnO}$ :Li films, reported in 1997 [115], showed the well-known blue-green emission typical of $\mathrm{ZnO}$ for the undoped films. The Li-doped films PL emission was a broad band composed of four overlapping peaks at 508, 590, 604 and $810 \mathrm{~nm}$ (the excitation wavelength was 
$365 \mathrm{~nm}$ ); the PL excitation spectra indicated that the excitation mechanism is primarily due to electron-hole pair generation across the $\mathrm{ZnO}$ energy bandgap. The decay time measurements of the PL showed that the lifetime of the luminescence emission was $187 \mathrm{~ns}$. The dependence of the luminescent intensity with temperature showed an activation energy of $0.057 \mathrm{eV}$ for competitive non-radiative transitions. These results were indicative that the lithium was atomically incorporated giving rise to a donor level in the $\mathrm{ZnO}$.

PL dependence on the deposition temperature, film thickness, and post heat treatment of $\mathrm{ZnO}$ films, deposited from $0.4 \mathrm{M}$ solution of zinc acetate dihydrate in a mixture of deionized water and isopropyl alcohol, was reported in 2000 [116]. Chlorine free $\mathrm{ZnO}$ films were obtained using zinc acetate as a precursor with the (002) oriented wurtzite structure in the substrate temperature range $250-350{ }^{\circ} \mathrm{C}$. For films with the same thickness, the intensity of green emission decreased with an increment of the $\mathrm{O} / \mathrm{Zn}$ ratio as determined by XPS. The green emission intensity was gradually enhanced with increasing film thickness. Increasing deposition temperatures resulted in a reduction of the $\mathrm{O} / \mathrm{Zn}$ ratio and an increment of the intensity of the green PL emission. Also, as the annealing temperature was increased, the $\mathrm{O} / \mathrm{Zn}$ ratio decreased, and the green emission was consequently enhanced.

The $\mathrm{CL}$ from $\mathrm{ZnO}$ and $\mathrm{ZnO}: \mathrm{F}$ ( 5 at.\%) films deposited from $\mathrm{ZnCl}_{2}$ precursor solutions and fluorine doped by adding $\mathrm{NH}_{4} \mathrm{~F}$ to spraying solution was reported in 2002 [117]. The optimal substrate temperature was $450{ }^{\circ} \mathrm{C}$ presenting a hexagonal close packed structure. The $\mathrm{CL}$ spectra of both $\mathrm{ZnO}$ and $\mathrm{ZnO}: \mathrm{F}$ films exhibited near-ultra-violet band peaked at $\lambda=382 \mathrm{~nm}$, but they differ on the visible emissions; the undoped $\mathrm{ZnO}$ films emitted an intense blue-green light at $520 \mathrm{~nm}$ and a red emission at $672 \mathrm{~nm}$, the fluorine doped samples presented a new band emission centered at $454 \mathrm{~nm}$ and no blue-green emission. This emission was interpreted as coming from a lattice modification of the $\mathrm{Zn}^{2+}$ environment in the crystal that could be due to a total anionic substitution process of $\mathrm{O}$ by $\mathrm{F}$ species.

Luminescent properties of $\mathrm{ZnO}$ and $\mathrm{ZnO}: \mathrm{Sn}$ (6 at.\%) films were studied through cathodoluminescence as well, in 2003 [118]. The spraying solutions $(0.05 \mathrm{M})$ were prepared from $\mathrm{Zn}$ and $\mathrm{Sn}$ chlorides dissolved in deionized water. The substrate temperature was fixed at $450{ }^{\circ} \mathrm{C}$. Luminescence films had a polycrystalline hexagonal wurtzite type structure. The CL measurements of the undoped films showed three bands centered at 382, 520 and $672 \mathrm{~nm}$. Incorporation of tin ions extinguishes the blue-green band $(520 \mathrm{~nm})$ while appears a blue light at $463 \mathrm{~nm}$ and increases the value of the band-gap transition. CL imaging of $\mathrm{ZnO}$ films showed that the luminescence was located at defined sites giving rise to a grain-like structure inherent to the surface morphology. The presence of $\mathrm{Sn}$ inside the films led to great luminescent spots, attributed to large grain sizes.

The photoluminescent properties of $\mathrm{Eu}^{2+}$ and $\mathrm{Eu}^{3+}$ ions in $\mathrm{ZnO}$ phosphors were reported in 2004 [119]. These particles were synthesized from a zinc acetate solution and europium nitrate as the europium ions source. The crystal structure (zincite) of samples depended on the europium ions and the synthesis temperature. It was identified the coexistence of $\mathrm{Eu}^{2+}$ and $\mathrm{Eu}^{3+}$ ions in the as prepared $\mathrm{ZnO}$ samples. With addition of a $0.5 \mathrm{~mol} \%$ concentration of europium ions, only the $\mathrm{Eu}^{2+}$ ion was detected inside the samples, while both $\mathrm{Eu}^{2+}$ and $\mathrm{Eu}^{3+}$ ions existed in samples using $1 \mathrm{~mol} \%$ or higher concentration of europium ions. Changing the excitation wavelength, it was observed that both the blue and red PL can be obtained. The reduction of the $\mathrm{Eu}^{3+}$ to $\mathrm{Eu}^{2+}$ ions occurred in the particles prepared by the addition of a low concentration of europium ions. This reduction changed the color of PL from red to blue. Blue PL can be enhanced by increasing the synthesis temperature. At a high concentration of europium ions, the $\mathrm{Eu}^{3+}$ created the $\mathrm{Eu}_{2} \mathrm{O}_{3}$ component forming a $\mathrm{ZnO}-\mathrm{Eu}_{2} \mathrm{O}_{3}$ composite.

The origin of the well-known blue-green emission of $\mathrm{ZnO}$ thin films was discussed on the basis of variation of the properties induced by different treatment of these films, such as ion beam irradiation (120 MeV Au ions and $80 \mathrm{MeV} \mathrm{Ni}$ ions were used for ion beam irradiation), and doping (Indium) [120]. PL studies of untreated thin films showed only one emission at $517 \mathrm{~nm}$ at room temperature while the irradiated films showed a decrease in this emission intensity. Indium doping also reduced the intensity of this emission; but additional emissions (centered at 407, 590 and $670 \mathrm{~nm}$ ) were observed in these 
thin films. It was proposed that the blue-green emission was due to the transitions from the bottom of the $\mathrm{ZnO}$ conduction band to the level associated with an oxygen antisite $\left(\mathrm{O}_{\mathrm{Zn}}\right)$.

Photoluminescence from Er-doped $\mathrm{ZnO}$ films were reported in 2008 [121]. These $\mathrm{ZnO}: \mathrm{Er}$ films were deposited on $\left(\begin{array}{lll}1 & 0 & 0\end{array}\right) \mathrm{MgO}$ wafers at $550{ }^{\circ} \mathrm{C}$; the concentration of Er ions in the deposition solution (from $\mathrm{Zn}$ and $\mathrm{Er}$ acetates in methanol at $0.1 \mathrm{M}$ ) varied from 1.0 to 3.0 at.\%. The films were polycrystalline with a dominant [002] preferential orientation. The near-ultraviolet (n-UV) PL from undoped $\mathrm{ZnO}$ films, n-UV peaks at 3.375 and $3.360 \mathrm{eV}$ were observed at $18 \mathrm{~K}$, which were proposed to be originated by free excitons and donor-bound excitons, respectively. The peaks from the free exciton transitions disappeared at room temperature. However, Er-doping enhanced the room temperature n-UV emission of ZnO:Er films. ZnO:Er (2.0 at.\%) films showed n-UV peaks which were 15 times stronger than those of undoped $\mathrm{ZnO}$ films.

Also, the luminescence of $\mathrm{ZnO}$ and $\mathrm{ZnO}$ :Ag nanocrystalline films deposited on $\mathrm{Si}\left(\begin{array}{lll}1 & 0 & 0\end{array}\right)$ substrates from aqueous solution prepared by Zinc acetate dehydrate and Silver nitrate (6 at.\%) was reported in 2008 [122]. Intrinsic samples deposited at $500{ }^{\circ} \mathrm{C}$ with spray rate of $0.15 \mathrm{~mL} / \mathrm{min}$ presented the best near-band edge near-ultraviolet emission at $378 \mathrm{~nm}$ observed within a set of samples deposited at different deposition temperature and spray rates. The PL intensity ratio of the n-UV emission to the deep-level emission had a largest value of 470 and the full-width at half-maximum of n-UV peak had a smallest value of $10 \mathrm{~nm}(87 \mathrm{meV})$. In addition, the $\mathrm{n}-\mathrm{UV}$ emission intensity of $\mathrm{ZnO}: \mathrm{Ag}$ films (with the Ag: $\mathrm{Zn}$ atomic ratio $=3 \%$ in the precursor solution) is markedly enhanced and the ratio to the deep-level emission, increased to at least 700. However, a silver phase was detected and the n-UV luminescence became weak for $\mathrm{ZnO}$ :Ag films after the annealing at $700{ }^{\circ} \mathrm{C}$ in air for $1 \mathrm{~h}$.

The electrical resistivity and the photoluminescence of zinc oxide films were correlated and reported in 2009 [123]. ZnO thin films were deposited, in this case, using zinc acetate dehydrate dissolved in methanol, ethanol, and deionized water within the substrate temperature range 320-420 ${ }^{\circ} \mathrm{C}$. PL measurements showed that the as-grown $\mathrm{ZnO}$ thin films exhibited ultraviolet and green emission bands when excited by an $\mathrm{Hg}$ arc lamp using $313 \mathrm{~nm}$ as the excitation source. A red-shift in the near band edge was observed with the increase in the deposition temperature and was attributed to the compressive intrinsic stress present into the films. It is confirmed that oxygen vacancy (VO) is the most important factor that causes the broad visible emission. Furthermore, the visible emission and electrical resistivity of $\mathrm{ZnO}$ thin films are found to be a function of porosity. Additionally, it has been found that the intensity of the green emission at $\sim 2.5 \mathrm{eV}$ increased when $\mathrm{ZnO}$ films were deposited at $320{ }^{\circ} \mathrm{C}$. The reason might be that the intrinsic stress, surface-to-volume ratio and porosity were incremented at low substrate temperatures. The resistivity presented similar behavior as the intensity of the green emission. A new luminescence mechanism based on the recombination related to oxygen vacancies in $\mathrm{Zn}$-rich or stoichiometric conditions, was proposed.

Another study about $\mathrm{ZnO}: \mathrm{Li}$ films was reported [124] for thin films deposited on borosilicate glass substrates; the deposition temperature was kept at $250{ }^{\circ} \mathrm{C}$. The spraying solution was $0.2 \mathrm{M}$ zinc acetate in a mixture of equal proportion of isopropyl alcohol and deionized water. Lithium doping was achieved by adding required amount of lithium acetate to the spraying solution. The spray time was $2 \mathrm{~min}$ with solution flow rate of $18 \mathrm{~cm}^{3} \cdot \mathrm{min}^{-1}$ and gas flow rate of $15 \mathrm{~L} \cdot \mathrm{min}^{-1}$. The polycrystalline nature of the films was confirmed from XRD and TEM studies. A two-dimensional fringe moiré pattern with spacing of $1.2 \mathrm{~nm}$ was observed for the Li doped thin films. Lithium doping increased the roughness of the surface, thus making the film more passivated. Lithium was founded to play a key role in the excitonic as well as visible PL of $\mathrm{ZnO}$ films.

The effect of introducing $\mathrm{Yb}$ ions into $\mathrm{ZnO}$ films was reported in 2011 [125]. Yb-doped ZnO thin films were deposited on glass substrates at $350{ }^{\circ} \mathrm{C}$ during $77 \mathrm{~min}$ with a flow rate of the solution fixed at $2.6 \mathrm{~mL} / \mathrm{min}$; the molar ratio of $\mathrm{Yb}$ in the spray solution was varied in the range of $0-5$ at.\%. XRD measurements showed that the undoped and Yb-doped ZnO films exhibit the hexagonal wurtzite crystal structure with a preferential orientation along [002] direction. All films exhibited a high transmittance. The PL measurements showed a band at $980 \mathrm{~nm}$ that is characteristic of $\mathrm{Yb}^{3+}$ transition 
between the electronic levels ${ }^{2} \mathrm{~F}_{5 / 2}$ and ${ }^{2} \mathrm{~F}_{7 / 2}$. This was an experimental evidence for an efficient energy transfer from $\mathrm{ZnO}$ matrix to $\mathrm{Yb}^{3+}$ ions. These films showed low resistivity and high carrier mobility which makes of interest to photovoltaic devices; all $\mathrm{ZnO}: \mathrm{Yb}$ thin films were n-type semiconductor. Also, $\mathrm{ZnO}: \mathrm{Yb}^{3+}$ films had potential as candidates for photons down conversion process.

An investigation of structural, optical and luminescent properties of sprayed N-doped zinc (NZO) oxide thin films was reported in 2012 [126]. The precursor solution (0.1 M of zinc acetate and $\mathrm{N}, \mathrm{N}$-dimethylformamide) was sprayed onto the preheated corning glass, and fluorine doped tin oxide substrates held at optimized substrate temperature of $450{ }^{\circ} \mathrm{C}$. Influence of $\mathrm{N}$ doping on structural, optical and luminescence properties were studied. These films were nanocrystalline having hexagonal crystal structure. Raman analysis depicted an existence of N-Zn-O structure in NZO thin film. XPS spectrum of $\mathrm{N} 1 \mathrm{~s}$ showed the $400 \mathrm{eV}$ peak terminally bonded, well screened molecular nitrogen $\left(\gamma-\mathrm{N}_{2}\right)$. Lowest direct band gap of $3.17 \mathrm{eV}$ was observed for 10 at.\% NZO thin film. The UV, blue and green deep-level emissions in PL of NZO films were due to $\mathrm{Zn}$ interstitials and $\mathrm{O}$ vacancies. The intensity of UV emission band increased with the concentration of activated nitrogen impurities. Shifting of PL peak from 393 to $388 \mathrm{~nm}$ seemed to be associated with free electron to neutral acceptor transition or some LO phonon replicas, followed by free electron-acceptor transitions.

The effect that $\mathrm{Ga}$ has on the properties of $\mathrm{ZnO}$ films deposited with an aqueous solution of $0.1 \mathrm{M}$ zinc acetate and gallium nitrate on corning glass substrates was reported in 2012 [127]. XRD study depicted that the films were polycrystalline with hexagonal crystal structure and strong orientations along the $\left(\begin{array}{lll}0 & 0 & 2\end{array}\right)$ and $\left(\begin{array}{lll}1 & 0 & 1\end{array}\right)$ planes. Presence of $E^{\text {high }} 2$ mode in Raman spectra indicated that the gallium doping does not affect the hexagonal structure. The $\mathrm{ZnO}: \mathrm{Ga}$ thin films were adherent, compact, densely packed with hexagonal flakes and spherical grains. Optical transmittance was high (about $80 \%$ ). PL spectra showed violet, blue and green emission in these films. The specific heat and thermal conductivity study showed that the phonon conduction behavior was dominant in these films. XPS analysis confirmed that the majority $\mathrm{Zn}$ atoms remain in the same formal valence state of $\mathrm{Zn}^{2+}$ within an oxygen-deficient $\mathrm{ZnO}$ host lattice. The presence of zinc and oxygen vacancies was confirmed from PL results. The potential use of these films for optoelectronic microdevices was considered possible.

Optical and structural characteristics of $\mathrm{ZnO}: \mathrm{Al}$ microrod films, obtained using different solvents (methanol and propanol), were published [128]. Zinc chloride at $0.1 \mathrm{M}$ concentration in methanol and propanol was used as spraying solution. The doping was achieved by the addition of Alq3 (tris(quinolin-8-olato) aluminum(III)) dissolved in chloroform with a concentration of 7 at.\% $\mathrm{Al}$; a $50 \mathrm{~nm} / \mathrm{min}$ deposition rate on glass substrates, at $500{ }^{\circ} \mathrm{C}$ and a spray rate of about $5 \mathrm{~mL} / \mathrm{min}$, was achieved. Both undoped $\mathrm{ZnO}$ and $\mathrm{ZnO}: \mathrm{Al}$ films were composed of microrods with hexagonal crystal structure and a $\left(\begin{array}{ll}0 & 0\end{array}\right)$ preferential orientation. SEM images revealed a quasi-aligned hexagonal shaped microrods with diameters varying between 0.7 and 1.3 micrometers. Optical studies showed that microrods had a low transmittance $(\sim 30 \%)$ and the band gap increased from 3.24 to $3.26 \mathrm{eV}$ upon $\mathrm{Al}$ doping. PL measurements showed the two emission bands usually present in $\mathrm{ZnO}$ PL spectra: One sharp and intense peak at $\sim 383 \mathrm{~nm}$ and one broadband ranging from 420 to $580 \mathrm{~nm}$.

The lithium effect on the blue and red emissions of $\mathrm{ZnO}: \mathrm{Er}$ thin films was reported in 2013 [129]. These films were successfully deposited on heated (at $450^{\circ} \mathrm{C}$ ) glass substrates. The spraying solution was $0.05 \mathrm{M}$ zinc chloride; erbium doping was achieved by adding $\mathrm{ErCl}_{3}$ in concentrations of 2, 3, 5, and 7 at.\%. Lithium was obtained from $\mathrm{Li}_{2} \mathrm{SO}_{4}$ in concentrations of 3, 5 and 7 at.\%. This study was an investigation of the Li effect on the enhancement of CL emission intensity on Er-mono doped $\mathrm{ZnO}$ films. The Li-Er co-doped $\mathrm{ZnO}$ films showed a higher $\mathrm{CL}$ intensity of blue and red emissions than the Er-mono doped $\mathrm{ZnO}$ films. This behavior was attributed to the modification of the local symmetry of the $\mathrm{Er}^{3+}$ ions, which increases the probabilities for the radiative intra $4 \mathrm{f}$ transition of the $\mathrm{Er}^{3+}$ ions to occur. These results suggested that optimized Er-Li-codoped $\mathrm{ZnO}$ films could be used in data storage devices. 
The blue luminescence of $\mathrm{ZnO}: \mathrm{Zn}$ nanocrystals prepared from zinc acetate dihydrate aqueous solutions $(0.05 \mathrm{M})$, and air as carrier gas with 1,3, and $5 \mathrm{~L} / \mathrm{min}$ flow rate was also reported in 2013 [130]. The temperature of the tubular reactor was set at 500,600, and $700{ }^{\circ} \mathrm{C}$. The crystal sizes were about 14-22 nm with a zincite structure; the observed morphology was partially spherical with other particles of irregular shape. The highest PL intensity, peaked at $450 \mathrm{~nm}$ (excitation wavelength of $250 \mathrm{~nm}$ ), was obtained from samples prepared using $5 \mathrm{~L} / \mathrm{min}$ carrier gas at $700{ }^{\circ} \mathrm{C}$. These PL emission was associated to oxygen vacancy in the $\mathrm{ZnO}: \mathrm{Zn}$ nanocrystals.

PL emission from $\mathrm{ZnO}$ :Ag films, formed by nanorods (NRs) as a function of the measurement temperature (10-300 K), was published in 2014 [131]. These films were deposited on soda-lime glass substrates at the deposition temperature of $400{ }^{\circ} \mathrm{C}$ and different deposition times (3, 5, and $\left.10 \mathrm{~min}\right)$. The spraying solution $(0.4 \mathrm{M})$ was prepared from zinc acetate and silver nitrate dissolved in in a mix of deionized water, acetic acid and methanol, a constant [Ag]/[Zn] ratio of 2 at.\% was used for $\mathrm{ZnO}$ : Ag films deposition. The de position time variation permitted modifying the $\mathrm{ZnO}$ phase from the amorphous to crystalline, to change the size of $\mathrm{ZnO}: \mathrm{Ag}$ NRs and to vary the PL emission spectra. PL spectra, versus temperature, revealed that the band related to the acceptor AgZn (LO phonon replicas of an acceptor bound exciton $(2.877 \mathrm{eV}))$, and its second-order diffraction peak $(1.44 \mathrm{eV})$ disappeared in the temperature range of $10-170 \mathrm{~K}$ with the formation of free exciton (FX). The PL intensity of defect related PL bands decreases monotonously in the range 10-300 K with the activation energy of $13 \mathrm{meV}$. The PL band $(3.22 \mathrm{eV})$, related to the LO phonon replica of free exciton (FX-2LO) and its second-order diffraction peak $(1.61 \mathrm{eV})$ increased in the range 10-300 K. FX related peak dominated in PL spectra at room temperature testifying the high quality of ZnO:Ag films deposited by the ultrasonic spray pyrolysis process.

A study on the role of substrates on the structural, optical, and morphological properties of $\mathrm{ZnO}$ films (nanotubes) was also reported in 2014 [132]. The role of substrate on the properties of $\mathrm{ZnO}$ films was investigated; these films were deposited onto glass, ITO coated glass and sapphire substrate and annealed at $400{ }^{\circ} \mathrm{C}$ for 3 hours. Aqueous solution $(0.1 \mathrm{M})$ of zinc acetate was used to deposit these films at $350{ }^{\circ} \mathrm{C}$. In the characterization XRD, SEM, Atomic force microscopy (AFM), and PL measurements were employed. XRD measurements showed that the $\mathrm{ZnO}$ films deposited on sapphire and ITO substrates exhibited a strong c-axis orientation of grains with hexagonal wurtzite structure. Extremely high UV emission intensity was observed in the film on ITO. The different luminescence behavior was discussed, which would be caused by least value of strain in the film-it is well known that the visible emission of $\mathrm{ZnO}$ thin films is due to the lattice defects that form deep energy levels in the bandgap. Films grown on different substrates revealed differences in the morphology. ZnO films on ITO and sapphire substrates revealed better morphology than that of the films deposited on glass. AFM images of the films prepared on ITO showed uniform distribution of grains with large surface roughness, suitable for application in dye sensitized solar cells. It was concluded that the nature of substrate had significant effect on the crystal structure, PL spectra, and morphological characteristics of the deposited $\mathrm{ZnO}$ films.

A comprehensive review on the structure, optical, and luminescence properties of $\mathrm{ZnO}: \mathrm{RE}$ nanophosphors, including up-conversion (UC) and down-conversion (DC) and/or down shifting PL, was published in 2017 [133]. Some of ZnO:RE nanophosphors reviewed were synthesized by spray pyrolysis technique. The interest on RE doped ZnO for UC and DC nanophosphors has been motivated by the potential application of these materials in light emitting microdevices and photovoltaic cells. The two characteristic emissions observed in $\mathrm{ZnO}$ at the ultraviolet and visible regions are related, respectively, to excitonic recombination and intrinsic defects. XPS data demonstrated a correlation between the visible emission and intrinsic defects in these phosphors. In the case of the DC or down shifting processes, there was simultaneous emission related to intra-f level transitions of the RE ions and defects associated transitions in the $\mathrm{ZnO}$ host lattice. These emissions were mainly dependent on the synthesis process, annealing temperature, and RE ion concentration; only $\mathrm{f} \rightarrow \mathrm{f}$ transitions of RE ions 
were observed in the case of the UC process. These down and up conversion RE doped $\mathrm{ZnO}$ phosphors were evaluated for a possible application in solid state lighting devices and photovoltaic cells.

Also, in 2017 a study on the morphological, structural and optical properties (PL and CL) of $\mathrm{ZnO}$ thin films formed by nanoleafs or micron/submicron cauliflowers was reported [134]. Precursor solution was composed of zinc acetate dihydrate in deionized water (resistivity: $18 \mathrm{M} \Omega \cdot \mathrm{cm}$ ); solution concentration was $0.002-0.064 \mathrm{~mol} \cdot \mathrm{dm}^{3}$ and reactor temperature was varied from 300 to $450^{\circ} \mathrm{C}$, in $50^{\circ} \mathrm{C}$ steps. These films formed by nano and microstructures with hexagonal crystal phase were successfully synthesized on aluminum or silicon substrates. The morphology showed the presence of three types of particles: Nano-leafs, single microparticles, and particles formed by the aglomeration of microparticles. The largest zone was formed by nanoleafs with a width of $25 \mathrm{~nm}$ and a length $200 \mathrm{~nm}$ long regardless of the roughness of the substrate. Moreover, the energy bandgap ( $3.26 \mathrm{eV})$ was invariant to changes in synthesis parameters. The optical measurements showed no considerable differences between the luminescence properties of films formed by nanoleafs and cauliflower particles. Deconvolution of PL emission spectra made it possible to elucidate the existence of oxygen vacancies, interstitial oxygen, zinc vacancies and interstitial zinc, structural defects in nanoleafs, and micro-cauliflowers. Defects such as these play an important role into PL and CL emissions of $\mathrm{ZnO}$ because electronic transitions associated to these defects originated almost the $100 \%$ of these emissions.

In 2018, a paper on the enhancement of visible luminescence and photocatalytic activity of $\mathrm{ZnO}: \mathrm{Cu}$ thin films was published [135]. ZnO thin films doped with copper (0-4 at.\%) were deposited on glass substrates maintaining a substrate temperature of $400 \pm 10^{\circ} \mathrm{C} .0 .4 \mathrm{M}$ solution of zinc acetate and cupric acetate dissolved in a mixture of methanol, deionized water and acetic acid was used as the precursor for the deposition of these thin films. Hexagonal crystallinity (wurtzite) of the films improved at lower doping concentrations due to the easy fitting of $\mathrm{Cu}$ dopants in the $\mathrm{Zn}$ host lattice sites and preferred highly textured growth along the $\left(\begin{array}{ll}0 & 0\end{array}\right)$ plane. Higher doping concentration deteriorated the crystallinity and the optical transmission. EDX measurements confirmed the incorporation of $\mathrm{Cu}$ in the doped films. Optical energy gap red-shifted with the addition of $\mathrm{Cu}$ contents due to the exchange interactions and difference in iconicity of $\mathrm{Zn}$ and $\mathrm{Cu}$. $\mathrm{Cu}$ doped films exhibited strong PL visible emission due to the modulation of the band structure and subsequently new levels acting as emission centers were formed in the forbidden bandgap of $\mathrm{ZnO}$ films. The addition of $\mathrm{Cu}$ ions increases the concentration of zinc interstitials, as well as zinc and oxygen vacancies which cause more intense emission in the visible region. $\mathrm{ZnO}: \mathrm{Cu}$ thin films exhibited very good photocatalytic activity due to the efficient trapping of photo-generated electrons thereby suppressing the electron-hole recombination and higher doping level slightly decreased the degradation efficiency because excess dopants may act as recombination centers.

The effect of fluorine and boron co-doped $\mathrm{ZnO}$ thin films on the structural and luminescence properties was published in 2018 [136]. Fluorine and boron co-doped zinc oxide (ZnO:B:F) thin films were deposited on the corning glass substrates at $400 \pm 5{ }^{\circ} \mathrm{C}$ : The spraying solution was prepared by mixing zinc acetate, boric acid, and ammonium fluoride, dissolved in methanol and deionized water with a ratio of 3:1. After characterization it was found that $\mathrm{ZnO}: \mathrm{B}: \mathrm{F}$ films had high average optical transmittance; XRD patterns indicated that the obtained $\mathrm{ZnO}: \mathrm{B}: \mathrm{F}$ films had a hexagonal wurtzite type structure with $\left(\begin{array}{ll}0 & 0\end{array}\right)$ preferential orientation. The crystallite sizes were in the 18-40 nm range. Green emission and UV emission band are observed in PL spectra of $\mathrm{ZnO}$ and $\mathrm{ZnO}: \mathrm{B}: \mathrm{F}$. Undoped $\mathrm{ZnO}$ films exhibited only one peak around $390 \mathrm{~nm}$ associated with near band ultra violet emission. It is well known that the UV emission peak usually originates from the near band-edge emission from the recombination of free exciton. Also, it was considered that the intensity ratio of UV to visible emission is commonly considered as a sign of perfect crystal quality and low defect concentration. A green emission peak was observed for ZnO:B:F films; the intensity of this peak centered at $520 \mathrm{~nm}$ increased while the B-F concentrations increased. The observed green emission is also due to the impurity levels related the oxygen vacancy (Vo) in $\mathrm{ZnO}: \mathrm{B}: \mathrm{F}$ films. The electrical resistivity, carrier concentration and Hall mobility also were measured. The highest Hall mobility of $13.22 \mathrm{~cm}^{2} \mathrm{v}^{-1} \cdot \mathrm{s}$, and the lowest 
electrical resistivity of $3.13 \times 10^{-4} \Omega \cdot \mathrm{cm}$, were obtained at the optimal boron-fluorine co-doping concentration of 5 at.\%. All of the results were appreciated in point of view of optoelectronic industry and photovoltaic solar cell applications and it was concluded that B-F co-doping has a positively effect on electrical properties.

\subsection{ZnS}

A research on the luminescence of $\mathrm{ZnS}, \mathrm{ZnS}: \mathrm{TbC1}_{3}$ and $\mathrm{ZnS}: \mathrm{SmCl}_{3}$ films, deposited by the Pneumatic SP technique, was first reported in 1988 [137]. The ZnS films were deposited using a spraying solution obtained by mixing in equal proportions solutions of $0.1 \mathrm{M}$ of $\mathrm{Zn}$ acetate and $0.1 \mathrm{M}$ of dimetylthiourea $\left(\mathrm{C}_{3} \mathrm{H}_{8} \mathrm{~N}_{2} \mathrm{~S}\right)$, both dissolved in three parts of isopropyl alcohol and one part of deionized water. The doped films were prepared by adding $\mathrm{TbCI}_{3} ;$ or $\mathrm{SmCI}_{3}$, to the spraying solution at a 10 at. $\%$ concentration; the substrate temperature, during the deposition, was either 300, 330, 360, or $375{ }^{\circ} \mathrm{C}$. The solution flow rate was $14 \mathrm{~cm}^{3} /$ minute and the nozzle substrate distance was $30 \mathrm{~cm}$ in all cases. The doped films exhibited strong PL emission with a blue dominant peak at about $460 \mathrm{~nm}$. This peak is characteristic of chlorine-doped ZnS phosphors. The films had poor crystallinity with a cubic crystalline structure. The optical transmission ( $T$ about $80 \%$ ) characteristics of these films showed an absorption edge shifted to shorter wavelengths compared with those of the undoped films. Photoluminescent characteristics of In-, Al-, and Cu-doped ZnS films were reported in 1989 [138]. These films were deposited from a spraying solution formed by $0.1 \mathrm{M}\left(\mathrm{CH}_{3} \mathrm{COO}\right)_{2}+0.1 \mathrm{M} \mathrm{C}_{3} \mathrm{H}_{8} \mathrm{~N}_{2} \mathrm{~S}$ dissolved in a mixture of three parts of isopropyl alcohol plus one part of deionized water. Doping was

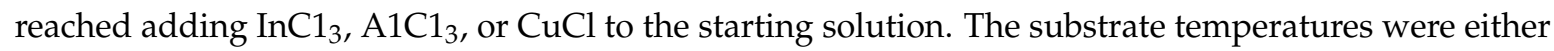
270,300 or $330^{\circ} \mathrm{C}$. The substrates were pyrex glass slides, pyrex glass coated with $\operatorname{In}_{2} \mathrm{O}_{3}$ and silicon oxide. All films showed polycrystalline features which could be associated to a wurtzite structure of $\mathrm{ZnS}$. Also, the presence of chlorine was detected into the films in quantities that depended on the deposition parameters. The PL spectra measured at room temperature displayed different emission peaks for each one of the impurities. The PL spectra from the Al-doped ZnS films showed a peak centered at $470 \mathrm{~nm}$. The In-doped ZnS films showed a peak about $545 \mathrm{~nm}$ and the PL spectrum from the $\mathrm{Cu}$-doped films exhibited a peak at $570 \mathrm{~nm}$. The shape and intensity of the PL spectra do not depend strongly on the type of substrate.

The luminescent properties of ZnS:Mn films deposited by the pyrolysis spray technique on glass substrates at atmospheric pressure using air as a carrier gas were reported, for the first time, in 1992 [139]. The spraying solution in this case consisted of $0.1 \mathrm{M}$ of $\mathrm{Zn}$ acetate and $0.1 \mathrm{M}$ of dimethylthiourea in a mixture of three parts of isopropyl alcohol and one part of deionized water. The Mn doping was achieved by mixing $\mathrm{MnCl}_{2}$ (0-20 at.\%) in the spraying solutions; the deposition temperature was varied between 340 and $500{ }^{\circ} \mathrm{C}$ in steps of $20^{\circ} \mathrm{C}$. All films resulted polycrystalline with a wurtzite (hexagonal) structure. The PL spectra show, besides the characteristic light emission associated with $\mathrm{Mn}$ (yellow at $590 \mathrm{~nm}$ ) in a $\mathrm{ZnS}$ host lattice, a peak associated with the self-activated emission (blue at $490 \mathrm{~nm}$ ) observable at low substrate temperatures and/or long deposition times. The presence of chlorine impurities in the films was suggested to be associated with this emission. The Mn related luminescence showed a quenching effect with the Mn concentration (at concentrations higher than 3 at.\% Mn in the spraying solution). The light emission at this center had an activation energy of $0.71 \pm 0.05 \mathrm{eV}$ with the deposition temperature. This energy was proposed to be related with the energy required for the $\mathrm{Mn}$ atoms to find a proper site during the growth process to form a $\mathrm{Mn}^{2+}$ center. These films were incorporated in a Metal-Insulator-active layer- Insulator-Metal (M-I-S-I-M) structure and their electroluminescent features were reported in 1995 [14]. These alternating current electroluminescent thin film structures were prepared using, for the first time, high-quality $\mathrm{SiO}_{2}$ insulating thin films and spray pyrolyzed $\mathrm{ZnS}: \mathrm{Mn}^{2+}$ as the active layer. The structures prepared with $60 \mathrm{~nm}$ thick insulating films showed threshold voltages of $30 \mathrm{~V}(\mathrm{rms})$ and saturation voltages of about $56 \mathrm{~V}(\mathrm{rms})$. The electroluminescent emission spectra presented a peak centered at $590 \mathrm{~nm}$ (yellow emission) associated with the $\mathrm{Mn}^{2+}$ center. The brightness-voltage characteristics were typical 
for a structure of the M-I-S-I-M type. The external efficiency calculated from the charge-voltage characteristics had a value of 1.8 Lumen/Watt.

Spray pyrolysis synthesis of ZnS nanoparticles (sub-10 $\mathrm{nm}$ ) from a single-source precursor was published in 2009 [140]. Here, it was reported the synthesis of cubic ZnS nanoparticles from a low-cost single-source precursor in a continuous spray pyrolysis reactor. In this study, a single-source precursor: Diethyldithiocarbamate, $\left[\left(\mathrm{C}_{2} \mathrm{H}_{5}\right)_{2} \mathrm{NCS}_{2}\right]_{2} \mathrm{Zn}$, dissolved in toluene was used to synthesize $\mathrm{ZnS}$ nanoparticles. The furnace setpoint temperature was typically $600-800{ }^{\circ} \mathrm{C}$. In this method, the evaporation and decomposition of precursor and nucleation of particles occur sequentially. XRD indicated a Cubic ZnS (zinc blende) for the synthesized particles. High Resolution Transmission Electron Microscopy (HRTEM) images showed ZnS particles with diameters ranging from 2 to $7 \mathrm{~nm}$ were. As-synthesized ZnS nanoparticles (excited at $350 \mathrm{~nm}$ ) exhibited blue photoluminescence near to $440 \mathrm{~nm}$ had quantum yields up to $15 \%$ after HF treatment. This demonstrated a potentially general approach for continuous low-cost synthesis of semiconductor quantum dots, and applications in solar cells, lasers and displays. Also, ZnS nanoparticles can be applied as phosphors, probes for bio-imaging, emitters in light emitting diodes and photocatalysts.

\section{Conclusions}

This review describes some of the very extensive research work about the spray pyrolysis technique, which without doubt, is an extraordinarily flexible and practical materials synthesis method. It is a low-cost, non-vacuum required, way to synthesize materials in the form of powders and films deposited over a wide variety of substrates, and can be easily adapted for large area deposition and industrial production processes. The present work has been limited to review several luminescent materials and those with high- $K$ dielectric properties, most of them metal oxides, synthesized by this process. Concerning the dielectric materials, it has been focused on the work carried out in high- $K$ dielectric films of aluminum oxide, yttrium oxide, and zirconium oxide, developed for application on MOSFET technology devices. Through the works reviewed, the spray pyrolysis technique has been proved to be a technique capable of producing films as thin as $30 \mathrm{~nm}$ on silicon wafers with an outstanding dielectric and optical qualities, which could also be considered for design and development of sensors and other multilayered microdevices-such as planar waveguides and resonant optical structures. In the case of luminescent materials ( $\mathrm{PL}, \mathrm{CL}, \mathrm{TL}, \mathrm{Up}$-conversion), the information reviewed shows that metal oxides $\left(\mathrm{ZrO}_{2}, \mathrm{HfO}_{2}, \mathrm{Al}_{2} \mathrm{O}_{3}, \mathrm{Y}_{2} \mathrm{O}_{3}, \mathrm{ZnO}\right)$ and $\mathrm{ZnS}$ doped with rare earth and transition metal ions with specific luminescent characteristics could be tailored according to light emitting devices, and to many other applications requirements.

Author Contributions: Writing-Review \& Editing, C.F.; Writing-Review of High K dielectrics section, M.A.A.-F.; Writing-Review of luminescent materials section, M.G.-H.

Funding: This research was funded by CINVESTAV IPN and CONACyT-Mexico grant number (CB-2015/253342).

Acknowledgments: J.U. Balderas and G.L. Jimenez for their technical support. Especial thanks to G. Righini for his invitation to write this review.

Conflicts of Interest: The authors declare no conflict of interest. The founding sponsors had no role in the design of the study; in the collection, analyses, or interpretation of data; in the writing of the manuscript, and in the decision to publish the results.

\section{References}

1. Viguie, J.C.; Spitz, J. Chemical Vapor Deposition at Low Temperatures. J. Electrochem. Soc. 1975, 122, 585-588. [CrossRef]

2. Kodas, T.T.; Hampden-Smith, M.J. Aerosol Processing of Materials; Wiley-VCH: New York, NY, USA, 1999; ISBN 0-471-24669-7.

3. Blandenet, G.; Court, M.; Lagarde, Y. Thin layers deposited by the pyrosol process. Thin Solid Films 1981, 77, 81-90. [CrossRef] 
4. Langlet, M.; Joubert, J.C. Chemistry of Advanced Materials; Rao, C.N.R., Ed.; Blackwell Science: Oxford, UK, 1993; Chapter 4; ISBN 0-632-03385-1.

5. Mwakikunga, B.W. Progress in Ultrasonic Spray Pyrolysis for Condensed Matter Sciences Developed From Ultrasonic Nebulization Theories since Michael Faraday. Crit. Rev. Solid State Mater. Sci. 2014, 39, 46-80. [CrossRef]

6. Patil, P.S. Versatility of chemical spray pyrolysis technique. Mater. Chem. Phys. 1999, 59, 185-198. [CrossRef]

7. Perednis, D.; Gauckler, L.J. Thin Film Deposition Using Spray Pyrolysis. J. Electroceram. 2005, 14, $103-111$. [CrossRef]

8. Ortiz, A.; Falcony, C.; García, M.; Sánchez, A. Terbium-doped zinc oxide films deposited by spray pyrolysis. J. Phys. D Appl. Phys. 1987, 20, 670-671. [CrossRef]

9. Aguilar-Frutis, M.; Garcia, M.; Falcony, C. Optical and electrical properties of aluminum oxide films deposited by spray pyrolysis. Appl. Phys. Lett. 1998, 72, 1700-1702. [CrossRef]

10. Carmona-Téllez, S.; Falcony, C.; Aguilar-Frutis, M.; Alarcón-Flores, G.; García-Hipólito, M.; Martínez-Martínez, R. White light emitting transparent double layer stack of $\mathrm{Al}_{2} \mathrm{O}_{3}: \mathrm{Eu}^{3+}, \mathrm{Tb}^{3+}$, and $\mathrm{Ce}^{3+}$ films deposited by spray pyrolysis. ECS J. Solid State Sci. Technol. 2013, 2, R111-R115. [CrossRef]

11. Jergel, M.; García, M.; Conde-Gallardo, A.; Falcony, C.; Canseco, M.A.; Plesch, G. Preliminary studies of thin metal oxide films prepared by deposition of an aerosol generated ultrasonically from aqueous nitrate solutions. Thin Solid Films 1997, 305, 157-163. [CrossRef]

12. Jergel, M.; Conde-Gallardo, A.; García, M.; Falcony, C.; Jergel, M. Metal oxide Co and Co-Fe-Cr films deposited on glass substrates from a metal-organic aerosol atomised by means of ultrasonic excitations. Thin Solid Films 1997, 305, 210-218. [CrossRef]

13. García, M.; Jergel, M.; Conde-Gallardo, A.; Falcony, C.; Plesch, G. Optical properties of Co and Co-Fe-Cr thin films deposited from an aerosol on glass substrates. Mater. Chem. Phys. 1998, 56, 21-26. [CrossRef]

14. García, M.; Alonso, J.C.; Falcony, C.; Ortiz, A. Alternating current electroluminescent devices prepared using low temperature remote plasma enhanced $\mathrm{CVD} \mathrm{SiO}_{2}$ and $\mathrm{ZnS}: \mathrm{Mn}$ deposited by spray pyrolysis. J. Phys. D Appl. Phys. 1995, 28, 223-225. [CrossRef]

15. Vázquez-Arreguín, R.; Aguilar-Frutis, M.; Falcony-Guajardo, C.; Castañeda-Galván, A.; Mariscal-Becerra, L.; Gallardo-Hernández, S.; Alarcón-Flores, G.; García-Rocha, M. Electrical, Optical and Structural Properties of $\mathrm{SnO}_{2}: \mathrm{Sb}: \mathrm{F}$ Thin Films Deposited from Sn(acac) $)_{2}$ by Spray Pyrolysis. ECS J. Solid State Sci. Technol. 2016, 5 , Q101-Q107. [CrossRef]

16. Alarcón-Flores, G.; Aguilar-Frutis, M.; Falcony, C.; García-Hipólito, M.; Araiza-Ibarra, J.J.; Herrera-Suárez, H.J. Low interface states and high dielectric constant $\mathrm{Y}_{2} \mathrm{O}_{3}$ films on Si substrates. J. Vac. Sci. Technol. B 2006, 24, 1873-1877. [CrossRef]

17. Reyna-García, G.; García-Hipólito, M.; Guzmán-Mendoza, J.; Aguilar-Frutis, M.; Falcony, C. Electrical, optical and structural characterization of high-k dielectric $\mathrm{ZrO}_{2}$ thin films deposited by the pyrosol technique. J. Mater. Sci.: Mater. Electron. 2004, 15, 439-446. [CrossRef]

18. Zaleta-Alejandre, E.; Meza-Rocha, A.N.; Rivera-Alvarez, Z.; Sandoval, I.M.; Araiza, J.J.; Aguilar-Frutis, M.; Falcony, C. Optical Characteristics of Silica Coatings Deposited by Ozone Assisted Spray Pyrolysis Technique. ECS J. Solid State Sci. Technol. 2013, 2, N145-N148. [CrossRef]

19. Carmona-Téllez, S.; Guzmán-Mendoza, J.; Aguilar-Frutis, M.; Alarcón-Flores, G.; García-Hipólito, M.; Canseco, M.A.; Falcony, C. Electrical, optical, and structural characteristics of $\mathrm{Al}_{2} \mathrm{O}_{3}$ thin films prepared by pulsed ultrasonic sprayed pyrolysis. J. Appl. Phys. 2008, 103, 034105. [CrossRef]

20. Aguilar-Frutis, M.; García, M.; Falcony, C.; Plesch, G.; Jimenez-Sandoval, S. A study of the dielectric characteristics of aluminum oxide thin films deposited by spray pyrolysis from $\mathrm{Al}$ (acac) 3 . Thin Solid Films 2001, 389, 200-206. [CrossRef]

21. Hou, X.; Choy, K.L. Processing and Applications of Aerosol-Assisted CVD. Chem. Vap. Depos. 2006, 12, 583-596. [CrossRef]

22. Avaru, B.; Patil, M.N.; Gogate, P.R.; Pandit, A.B. Ultrasonic atomization: Effect of liquid phase properties. Ultrasonics 2006, 44, 146-158. [CrossRef] [PubMed]

23. Ukoba, K.O.; Eloka-Eboka, A.C.; Inambao, F.L. Review of nanostructured $\mathrm{NiO}$ thin film deposition using the spray pyrolysis Technique. Renew. Sustain. Energy Rev. 2018, 82, 2900-2915. [CrossRef] 
24. Filipovic, L.; Selberherr, S.; Mutinati, G.C.; Brunet, E.; Steinhauer, S.; Köck, A.; Teva, J.; Kraft, J.; Siegert, J.; Schrank, F. Methods of simulating thin film deposition using spray pyrolysis Techniques. Microelectron. Eng. 2014, 117, 57-66. [CrossRef]

25. Robertson, J. High dielectric constant gate oxides for metal oxide Si transistors. J. Rep. Prog. Phys. 2006, 69, 327-396. [CrossRef]

26. Wilk, G.D.; Wallace, R.M.; Anthony, J.M. High-k gate dielectrics: Current status and materials properties considerations. J. Appl. Phys. 2001, 89, 5243-5275. [CrossRef]

27. Ishida, M.; Katakabe, I.; Nakamura, T.; Ohtake, N. Epitaxial $\mathrm{Al}_{2} \mathrm{O}_{3}$ films on Si by low-pressure chemical vapor deposition. Appl. Phys. Lett. 1988, 52, 1326-1328. [CrossRef]

28. Sawada, K.; Ishida, M.; Nakamura, T.; Ohtake, N. Metalorganic molecular beam epitaxy of $\gamma-\mathrm{Al}_{2} \mathrm{O}_{3}$ films on Si at low growth temperatures. Appl. Phys. Lett. 1988, 52, 1672-1674. [CrossRef]

29. Saraie, J.S.; Ngan, S. Photo-CVD of $\mathrm{Al}_{2} \mathrm{O}_{3}$ Thin Films. Jpn. J. Appl. Phys. 1990, 29, L1877-L1880. [CrossRef]

30. Dhonge, B.P.; Mathews, T.; Sundari, S.T.; Thinaharan, C.; Kamruddin, M.; Dash, S.; Tyagi, A.K. Spray pyrolytic deposition of transparent aluminum oxide $\left(\mathrm{Al}_{2} \mathrm{O}_{3}\right)$ films. Appl. Surf. Sci. 2011, 258, 1091-1096. [CrossRef]

31. Khatibani, A.B.; Rozati, S.M. Growth and molarity effects on properties of alumina thin films obtained by spray pyrolysis. Mater. Sci. Semicond. Process. 2014, 18, 80-87. [CrossRef]

32. Sanchez-Alarcón, R.I.; Oropeza-Rosario, G.; Gutiérrez-Villalobos, A.; Muro-López, M.A.; Martínez-Martínez, R.; Zaleta-Alejandre, E.; Falcony, C.; Alarcón-Flores, G.; Fragoso, R.; Hernández-Silva, O.; et al. Ultrasonic spray-pyrolyzed $\mathrm{CuCrO}_{2}$ thin films. J. Phys. D Appl. Phys. 2016, 49, 175102. [CrossRef]

33. Kim, J.S.; Marzouk, H.A.; Reucroft, P.J.; Robertson, J.D.; Hamrin, C.E. Fabrication of aluminum oxide thin films by low-pressure metalorganic chemical vapor deposition technique. Appl. Phys. Lett. 1993, 62, 681-683. [CrossRef]

34. Alarcón-Flores, G.; Aguilar-Frutis, M.; García-Hipólito, M.; Guzmán-Mendoza, J.; Canseco, M.A.; Falcony, C. Optical and structural characteristics of $\mathrm{Y}_{2} \mathrm{O}_{3}$ thin films synthesized from yttrium acetylacetonate. J. Mater. Sci. 2008, 43, 3582-3588. [CrossRef]

35. Ronda, C.R. (Ed.) Luminescence: From Theory to Applications; Wiley-VCH Verlag GmbH \& Co. KGaA: Weinheim, Germany, 2008; ISBN 978-3-527-31402-7.

36. Vij, D.R. (Ed.) Luminescence of Solids; Plenum Press: New York, NY, USA, 1998; ISBN 0-306-45643-5.

37. Blasse, G.; Grabmaier, B.C. Luminescent Materials; Springer: Berlin/Heidelberg, Germany, 1994; ISBN 3-540-58019-0.

38. Yen, W.M.; Shionoya, S.; Yamamoto, H. (Eds.) Phosphor Handbook, 2nd ed.; CRC Press: Boca Raton, FL, USA, 2007; ISBN 0-8493-3564-7.

39. Félix-Quintero, H.; Angulo-Rocha, J.; Murrieta, S.H.; Hernández, A.J.; Camarillo, G.E.; Flores, J.M.C.; Alejo-Armenta, C.; García-Hipolito, M.; Ramos-Brito, F. Study on grow process and optical properties of $\mathrm{ZnO}$ microrods synthesized by hydrothermal method. J. Lumin. 2017, 182, 107-113. [CrossRef]

40. Montes, E.; Martínez-Merlín, I.; Guzmán-Olguín, J.C.; Guzmán-Mendoza, J.; Martín, I.R.; García-Hipólito, M.; Falcony, C. Effect of $\mathrm{pH}$ on the optical and structural properties of $\mathrm{HfO}_{2}: \mathrm{Ln}^{3+}$, synthesized by hydrothermal route. J. Lumin. 2016, 175, 243-248. [CrossRef]

41. Jiang, Y.; Chen, J.; Xie, Z.; Zheng, L. Syntheses and optical properties of $\alpha$ - and $\beta-\mathrm{Zn}_{2} \mathrm{SiO}_{4}$ : Mn nanoparticles by solvothermal method in ethylene glycol-water system. Mater. Chem. Phys. 2010, 120, 313-318. [CrossRef]

42. Park, K.; Kim, H.; Hakeem, D.A. Photoluminescence properties of $\mathrm{Eu}^{3+}$ - and $\mathrm{Tb}^{3+}$-doped $\mathrm{YAlO}_{3}$ phosphors for White LED applications. Ceram. Int. 2016, 42, 10526-10530. [CrossRef]

43. El-Ghoul, J.; Omri, K.; Alyamani, A.; Barthou, C.; El-Mir, L. Synthesis and luminescence of $\mathrm{SiO}_{2} / \mathrm{Zn}_{2} \mathrm{SiO}_{4}$ and $\mathrm{SiO}_{2} / \mathrm{Zn}_{2} \mathrm{SiO}_{4}$ :Mn composite with sol-gel methods. J. Lumin. 2013, 138, 218-222. [CrossRef]

44. Pereyra-Perea, E.; Estrada-Yañez, M.R.; García, M. Preliminary studies on luminescent terbium-doped $\mathrm{ZrO}_{2}$ thin films prepared by the sol-gel process. J. Phys. D Appl. Phys. 1998, 31, L7-L10. [CrossRef]

45. Alonso, J.C.; Haro-Poniatowski, E.; Diamant, R.; Fernandez-Guasti, M.; Garcia, M. Photoluminescent thin films of terbium chloride-doped yttrium oxide deposited by the pulsed laser ablation technique. Thin Solid Films 1997, 303, 76-83. [CrossRef]

46. Aguilar-Castillo, A.; Aguilar-Hernández, J.R.; García-Hipólito, M.; López-Romero, S.; Swarnkar, R.K.; Báez-Rodríguez, A.; Fragoso-Soriano, R.J.; Falcony, C. White light generation from $\mathrm{HfO}_{2}$ films co-doped with $\mathrm{Eu}^{3+}+\mathrm{Tb}^{3+}$ ions synthesized by pulsed laser ablation technique. Ceram. Int. 2017, 43, 355-362. [CrossRef] 
47. Liu, L.; Wang, Y.; Su, Y.; Ma, Z.; Xie, Y.; Zhao, H.; Chen, C.; Zhang, Z.; Xie, E. Synthesis and White Light Emission of Rare Earth-Doped $\mathrm{HfO}_{2}$ Nanotubes. J. Am. Ceram. Soc. 2011, 94, 2141-2145. [CrossRef]

48. Deng, H.; Xue, N.; Hei, Z.; He, M.; Wang, T.; Xie, N.; Yu, R. Close-relationship between the luminescence and structural characteristics in efficient nanophosphor $\mathrm{Y}_{2} \mathrm{Mo}_{4} \mathrm{O}_{15}: \mathrm{Eu}^{3+}$. Opt. Mater. Express 2015, 5, 490-496. [CrossRef]

49. Stojadinović, S.; Tadić, N.; Vasilić, R. Structural and photoluminescent properties of $\mathrm{ZrO}_{2}: \mathrm{Tb}^{3+}$ coatings formed by plasma electrolytic oxidation. J. Lumin. 2018, 197, 83-89. [CrossRef]

50. Yasaka, P.; Kaewkhao, J. White emission materials from glass doped with rare earth ions: A review. AIP Conf. Proc. 2016, 1719, 020002. [CrossRef]

51. Félix-Quintero, H.; Camarillo-Garcia, I.; Hernández-Alcántara, J.; Camarillo-García, E.; Cordero-Borboa, A.; Flores-Jiménez, C.; García-Hipólito, M.; Ramos-Brito, F.; Acosta-Najarro, D.; Murrieta-Sánchez, H. RGB emission of $\mathrm{Mn}^{2+}$ doped zinc phosphate glass. J. Non-Cryst. Solids 2017, 466-467, 58-63. [CrossRef]

52. Rakov, N.; Bispo, L.R.A.; Maciel, G.S. Temperature sensing performance of dysprosium doped aluminum oxide powders. Opt. Commun. 2012, 285, 1882-1884. [CrossRef]

53. Cedillo Del Rosario, G.; Cruz-Zaragoza, E.; García-Hipólito, M.; Marcazzó, J.; Hernández-A, J.M.; Murrieta-S, H. Synthesis and stimulated luminescence property of $\mathrm{Zn}\left(\mathrm{BO}_{2}\right)_{2}: \mathrm{Tb}^{3+}$. Appl. Radiat. Isot. 2017, 127, 103-108. [CrossRef] [PubMed]

54. Roman-Lopez, J.; Valverde, M.; García-Hipólito, M.; Lozano, I.B.; Diaz-Góngora, J.A.I. Photoluminescence, thermo- and optically stimulated luminescence properties of $\mathrm{Eu}^{3+}$ doped $\mathrm{Sr}_{2} \mathrm{P}_{2} \mathrm{O}_{7}$ synthesized by the solvent evaporation method. J. Alloys Compd. 2018, 756, 126-133. [CrossRef]

55. García-Hipólito, M.; Falcony, C.; Aguilar-Frutis, M.A.; Azorín-Nieto, J. Synthesis and characterization of luminescent $\mathrm{ZrO}_{2}: \mathrm{Mn}, \mathrm{Cl}$ powders. Appl. Phys. Lett. 2001, 79, 4369-4371. [CrossRef]

56. Ramos-Brito, F.; García-Hipólito, M.; Martínez-Martínez, R.; Martínez-Sánchez, E.; Falcony, C. Preparation and characterization of photoluminescent praseodymium-doped $\mathrm{ZrO}_{2}$ nanostructured powders. J. Phys. D Appl. Phys. 2004, 37, L13-L16. [CrossRef]

57. Ortiz, A.; Falcony, C.; García, M.; López, S. Spray deposition of $\mathrm{TbCl}_{3}$ doped $\mathrm{In}_{2} \mathrm{O}_{3}$ photoluminiscent films. Thin Solid Films 1988, 165, 249-255. [CrossRef]

58. Calderón-Olvera, R.M.; Albanés-Ojeda, E.A.; García-Hipólito, M.; Hernández-Alcántara, J.M.; Álvarez-Perez, M.A.; Falcony, C.; Alvarez-Fregoso, O. Characterization of luminescent $\mathrm{SrAl}_{2} \mathrm{O}_{4}$ films doped with terbium and europium ions deposited by ultrasonic spray pyrolysis technique. Ceram. Int. 2018, 44, 7917-7925. [CrossRef]

59. Azorín, J.; Rivera, T.; Falcony, C.; Martínez, E.; García, M. Ultraviolet thermoluminescent dosimetry using terbium-doped zirconium oxide thin films. Radiat. Prot. Dosim. 1999, 85, 317-319. [CrossRef]

60. Rivera, T.; Azorín, J.; Falcony, C.; Martínez, E.; García, M. Determination of thermoluminescence kinetic parameters of terbium-doped zirconium oxide. Radiat. Phys. Chem. 2001, 61, 421-423. [CrossRef]

61. García-Hipólito, M.; Martínez, R.; Alvarez-Fregoso, O.; Martínez, E.; Falcony, C. Cathodoluminescence and photoluminescence properties of terbium doped $\mathrm{ZrO}_{2}$ films prepared by pneumatic spray pyrolysis technique. J. Lumin. 2001, 93, 9-15. [CrossRef]

62. García-Hipólito, M.; Martínez, E.; Alvarez-Fregoso, O.; Falcony, C.; Aguilar-Frutis, M.A. Preparation and characterization of Eu doped zirconia luminescent films synthesized by pyrosol technique. J. Mater. Sci. Lett. 2001, 20, 1799-1801. [CrossRef]

63. García-Hipólito, M.; Alvarez-Fregoso, O.; Martínez, E.; Falcony, C.; Aguilar-Frutis, M.A. Characterization of $\mathrm{ZrO}_{2}: \mathrm{Mn}, \mathrm{Cl}$ luminescent coatings synthesized by the pyrosol technique. Opt. Mater. 2002, 20, 113-118. [CrossRef]

64. Quan, Z.W.; Wang, L.S.; Lin, J. Synthesis and characterization of spherical $\mathrm{ZrO}_{2}: \mathrm{Eu}^{3+}$ phosphors by spray pyrolysis process. Mater. Res. Bull. 2005, 40, 810-820. [CrossRef]

65. Ramos-Brito, F.; García-Hipólito, M.; Alejo-Armenta, C.; Alvarez-Fregoso, O.; Falcony, C. Characterization of luminescent praseodymiun-doped $\mathrm{ZrO}_{2}$ coatings deposited by ultrasonic spray pyrolysis technique. J. Phys. D Appl. Phys. 2007, 40, 6718-6724. [CrossRef]

66. Martínez-Hernández, A.; Guzmán-Mendoza, J.; Rivera-Montalvo, T.; Sánchez-Guzmán, D.; Guzmán-Olguín, J.C.; García-Hipólito, M.; Falcony, C. Synthesis and cathodoluminescence characterization of $\mathrm{ZrO}_{2}: \mathrm{Er}^{3+}$ films. J. Lumin. 2014, 153, 140-143. [CrossRef] 
67. Báez-Rodríguez, A.; Alvarez-Fregoso, O.; García-Hipólito, M.; Guzmán-Mendoza, J.; Falcony, C. Luminescent properties of $\mathrm{ZrO}_{2}: \mathrm{Dy}^{3+}$ and $\mathrm{ZrO}_{2}: \mathrm{Dy}^{3+}+\mathrm{Li}^{+}$films synthesized by an ultrasonic spray pyrolysis technique. Ceram. Int. 2015, 41, 7197-7206. [CrossRef]

68. Martínez-Olmos, R.C.; Guzmán-Mendoza, J.; Báez-Rodríguez, A.; Alvarez-Fregoso, O.; García-Hipólito, M.; Falcony, C. Synthesis, characterization and luminescence studies in $\mathrm{ZrO}_{2}: \mathrm{Dy}^{3+}$ and $\mathrm{ZrO}_{2}: \mathrm{Dy}^{3+}, \mathrm{Gd}^{3+}$ films deposited by the Pyrosol method. Opt. Mater. 2015, 46, 168-174. [CrossRef]

69. Ramos-Guerra, A.I.; Guzmán-Mendoza, J.; García-Hipólito, M.; Alvarez-Fregoso, O.; Falcony, C. Multicolored photoluminescence and structural properties of zirconium oxide films co-doped with $\mathrm{Tb}^{3+}$ and $\mathrm{Eu}^{3+}$ ions. Ceram. Int. 2015, 41, 11279-11286. [CrossRef]

70. Falcony, C.; Ortiz, A.; Dominguez, J.M.; Farías, M.H.; Cota-Araiza, L.; Soto, G. Luminescent Characteristics of $\mathrm{Tb}$ Doped $\mathrm{Al}_{2} \mathrm{O}_{3}$ Films Deposited by Spray Pyrolysis. J. Electrochem. Soc. 1992, 139, 267-271. [CrossRef]

71. Falcony, C.; García, M.; Ortiz, A.; Miranda, O.; Gradilla, I.; Soto, G.; Cota-Araiza, L.; Farías, M.H.; Alonso, J.C. Blue Photoluminescence from $\mathrm{CeCl}_{3}$ Doped $\mathrm{Al}_{2} \mathrm{O}_{3}$ Films. J. Electrochem. Soc. 1994, 141, 2860-2863. [CrossRef]

72. Martínez, E.; García, M.; Ramos-Brito, F.; Alvarez-Fregoso, O.; López, S.; Granados, S.; Chavez-Ramírez, J.; Martinez-Martinez, R.; Falcony, C. Characterization of $\mathrm{Al}_{2} \mathrm{O}_{3}: \mathrm{Eu}^{3+}$ luminescent coatings prepared by Spray Pyrolysis Technique. Phys. Status Solidi B 2000, 220, 677-681. [CrossRef]

73. Esparza-García, A.E.; García-Hipólito, M.; Aguilar-Frutis, M.A.; Falcony, C. Luminescent and morphological characteristics of $\mathrm{Al}_{2} \mathrm{O}_{3}: \mathrm{Tb}$ films deposited by spray pyrolysis using acetylacetonates as precursors. J. Electrochem. Soc. 2003, 150, H53-H56. [CrossRef]

74. Martinez-Martinez, R.; García-Hipólito, M.; Ramos-Brito, F.; Hernandez-Pozos, J.L.; Caldiño, U.; Falcony, C. Blue and red photoluminescence from $\mathrm{Al}_{2} \mathrm{O}_{3}: \mathrm{Ce}: \mathrm{Mn}$ films deposited by spray pyrolysis. J. Phys. Condens. Matter 2005, 17, 3647-3656. [CrossRef]

75. Martinez-Martinez, R.; Rickards, J.; García-Hipólito, M.; Trejo-Luna, R.; Martínez-Sánchez, E.; Alvarez-Fregoso, O.; Ramos-Brito, F.; Falcony, C. RBS characterization of $\mathrm{Al}_{2} \mathrm{O}_{3}$ films doped with $\mathrm{Ce}$ and Mn. Nucl. Instrum. Methods Phys. Res. Sect. B 2005, 241, 450-453. [CrossRef]

76. Martinez-Martinez, R.; García-Hipólito, M.; Huerta, L.; Rickards, J.; Caldiño, U.; Falcony, C. Studies on blue and red photoluminescence from $\mathrm{Al}_{2} \mathrm{O}_{3}: \mathrm{Ce}^{3+}: \mathrm{Mn}^{2+}$ coatings synthesized by spray pyrolysis technique. Thin Solid Films 2006, 515, 607-610. [CrossRef]

77. Martinez-Martinez, R.; Alvarez, E.; Speghini, A.; Falcony, C.; Caldiño, U. White light generation in $\mathrm{Al}_{2} \mathrm{O}_{3}: \mathrm{Ce}^{3+}: \mathrm{Tb}^{3+}: \mathrm{Mn}^{2+}$ films deposited by ultrasonic spray pyrolysis. Thin Solid Films 2010, 518, 5724-5730. [CrossRef]

78. Martinez-Martinez, R.; Rivera, S.; Yescas-Mendoza, E.; Alvarez, E.; Falcony, C.; Caldiño, U. Luminescence properties of $\mathrm{Ce}^{3+}-\mathrm{Dy}^{3+}$ codoped aluminium oxide films. Opt. Mater. 2011, 33, 1320-1324. [CrossRef]

79. Gonzalez, W.; Alvarez, E.; Martinez-Martinez, R.; Yescas-Mendoza, E.; Camarillo, I.; Caldiño, U. Cold white light generation through the simultaneous emission from $\mathrm{Ce}^{3+}, \mathrm{Dy}^{3+}$ and $\mathrm{Mn}^{2+}$ in $90 \mathrm{Al}_{2} \mathrm{O}_{3} \cdot 2 \mathrm{CeCl}_{3} \cdot 3 \mathrm{DyCl}_{3} \cdot 5 \mathrm{MnCl}_{2}$ thin film. J. Lumin. 2012, 132, 2130-2134. [CrossRef]

80. Huerta, E.F.; Padilla, I.; Martinez-Martinez, R.; Hernandez-Pozos, J.L.; Caldiño, U.; Falcony, C. Extended decay times for the photoluminescence of $\mathrm{Eu}^{3+}$ ions in aluminum oxide films through interaction with localized states. Opt. Mater. 2012, 34, 1137-1142. [CrossRef]

81. Martínez-Martínez, R.; Yescas, E.; Álvarez, E.; Falcony, C.; Caldiño, U. White light generation in rare-earth-doped amorphous films produced by ultrasonic spray pyrolysis. Adv. Sci. Technol. 2013, 82, 19-24. [CrossRef]

82. Padilla-Rosales, I.; Martinez-Martinez, R.; Cabañas, G.; Falcony, C. The effect of $\mathrm{Bi}^{3+}$ and $\mathrm{Li}^{+}$co-doping on the luminescence characteristics of $\mathrm{Eu}^{3+}$-doped aluminum oxide films. J. Lumin. 2015, 165, 185-189. [CrossRef]

83. García-Hipólito, M.; Alvarez-Fragoso, O.; Guzmán, J.; Martínez, E.; Falcony, C. Characterization of $\mathrm{HfO}_{2}: \mathrm{Mn}$ luminescent coatings deposited by spray pyrolysis. Phys. Status Solidi A 2004, 201, R127-R130. [CrossRef]

84. García-Hipólito, M.; Caldiño, U.; Alvarez-Fragoso, O.; Alvarez-Pérez, M.A.; Martínez-Martínez, R.; Falcony, C. Violet-blue luminescence from hafnium oxide layers doped with $\mathrm{CeCl}_{3}$ prepared by the spray pyrolysis technique. Phys. Status Solidi A 2007, 204, 2355-2361. [CrossRef]

85. Guzmán-Mendoza, J.; Albarran-Arreguín, D.; Alvarez-Fragoso, O.; Alvarez-Pérez, M.A.; Falcony, C.; García-Hipólito, M. Photoluminescent characteristics of hafnium oxide layers activated with trivalent terbium $\left(\mathrm{HfO}_{2}: \mathrm{Tb}^{+3}\right)$. Radiat. Eff. Defects Solids 2007, 162, 723-729. [CrossRef] 
86. Chacón-Roa, C.; Guzmán-Mendoza, J.; Aguilar-Frutis, M.A.; García-Hipólito, M.; Alvarez-Fragoso, O.; Falcony, C. Characterization of luminescent samarium doped $\mathrm{HfO}_{2}$ coatings synthesized by spray pyrolysis technique. J. Phys. D Appl. Phys. 2008, 41, 015104. [CrossRef]

87. Martınez-Martınez, R.; García-Hipólito, M.; Speghini, A.; Bettinelli, M.; Falcony, C.; Caldiño, U. Blue-green-red luminescence from $\mathrm{CeCl}_{3}$ - and $\mathrm{MnCl}_{2}$ - doped hafnium oxide layers prepared by ultrasonic spray pyrolysis. J. Phys. Condens. Matter. 2008, 20, 395205. [CrossRef]

88. Martınez-Martınez, R.; Alvarez, E.; Speghini, A.; Falcony, C.; Caldiño, U. Cold white light generation from hafnium oxide films activated with $\mathrm{Ce}^{3+}, \mathrm{Tb}^{3+}$, and $\mathrm{Mn}^{2+}$ ions. J. Mater. Res. 2010, 25, 484-490. [CrossRef]

89. Guzmán-Mendoza, J.; Aguilar-Frutis, M.A.; Alarcón-Flores, G.; García-Hipólito, M.; Maciel-Cerda, A.; Azorín-Nieto, J.; Rivera-Montalvo, T.; Falcony, C. Synthesis and characterization of hafnium oxide films for thermo and photoluminescence applications. Appl. Radiat. Isot. 2010, 68, 696-699. [CrossRef]

90. Martınez-Martınez, R.; Lira, A.C.; Speghini, A.; Falcony, C.; Caldiño, U. Blue-yellow photoluminescence from $\mathrm{Ce}^{3+} \rightarrow \mathrm{Dy}^{3+}$ energy transfer in $\mathrm{HfO}_{2}: \mathrm{Ce}^{3+}: \mathrm{Dy}^{3+}$ films deposited by ultrasonic spray pyrolysis. J. Alloys Compd. 2011, 509, 3160-3165. [CrossRef]

91. Reynoso-Manríquez, R.; Díaz-Góngora, J.A.I.; Guzmán-Mendoza, J.; Rivera-Montalvo, T.; Guzmán-Olguín, J.C.; Cerón-Ramírez, P.V.; García-Hipólito, M.; Falcony, C. Photo, -cathodo- and thermoluminescent properties of dysprosium-doped $\mathrm{HfO}_{2}$ films deposited by ultrasonic spray pyrolysis. Appl. Radiat. Isot. 2014, 92, 91-95. [CrossRef] [PubMed]

92. Martínez-Merlín, I.; Guzmán-Mendoza, J.; García-Hipólito, M.; Sánchez-Resendiz, V.M.; Lartundo-Rojas, R.J.; Fragoso, R.J.; Falcony, C. Transparent and low Surface roughness $\mathrm{HfO}_{2}: \mathrm{Tb}^{3+}, \mathrm{Eu}^{3+}$ luminescent thin films deposited by USP technique. Ceram. Int. 2016, 42, 2446-2455. [CrossRef]

93. Guzman-Olguin, J.C.; Montes, E.; Guzmán-Mendoza, J.; Baez-Rodrıguez, A.; Zamora-Peredo, L.; García-Hipólito, M.; Alvarez-Fregoso, O.; Martínez-Merlín, I.; Falcony, C. Tunable white light emission from hafnium oxide films co-doped with trivalent terbium and europium ions deposited by Pyrosol technique. Phys. Status Solidi A 2017, 214, 1700269. [CrossRef]

94. Kang, Y.C.; Roh, H.S.; Park, S.B. Preparation of $\mathrm{Y}_{2} \mathrm{O}_{3}$ :Eu phosphor particles of filled morphology at high precursor concentrations by Spray Pyrolysis. Adv. Mater. 2000, 12, 451-453. [CrossRef]

95. Hao, J.; Studenikin, S.A.; Cocivera, M. Blue, green and red cathodoluminescence of $\mathrm{Y}_{2} \mathrm{O}_{3}$ phosphor films prepared by spray pyrolysis. J. Lumin. 2001, 93, 313-319. [CrossRef]

96. Kang, Y.C.; Roh, H.S.; Park, S.B.; Park, H.D. Use of $\mathrm{LiCl}$ flux in the preparation of $\mathrm{Y}_{2} \mathrm{O}_{3}$ :Eu phosphor particles by spray pyrolysis. J. Eur. Ceram. Soc. 2002, 22, 1661-1665. [CrossRef]

97. Kang, Y.C.; Roh, H.S.; Park, S.B.; Park, H.D. High luminescence $\mathrm{Y}_{2} \mathrm{O}_{3}$ :Eu phosphor particles prepared by modified spray pyrolysis. J. Mater. Sci. Lett. 2002, 21, 1027-1029. [CrossRef]

98. Joffin, N.; Dexpert-Ghys, J.; Verelst, M.; Baret, G.; Garcia, A. The influence of microstructure on luminescent properties of $\mathrm{Y}_{2} \mathrm{O}_{3}$ :Eu prepared by spray pyrolysis. J. Lumin. 2005, 113, 249-257. [CrossRef]

99. Wang, L.S.; Zhou, Y.H.; Quan, Z.W.; Lin, J. Formation mechanisms and morphology dependent luminescence properties of $\mathrm{Y}_{2} \mathrm{O}_{3}$ :Eu phosphors prepared by spray pyrolysis process. Mater. Lett. 2005, 59, 1130-1133. [CrossRef]

100. Jungz, K.Y.; Han, K.H. Densification and Photoluminescence Improvement of $\mathrm{Y}_{2} \mathrm{O}_{3}$ Phosphor Particles Prepared by Spray Pyrolysis. Electrochem. Solid-State Lett. 2005, 8, H17-H20. [CrossRef]

101. Marinkovic, K.; Mancic, L.; Gomez, L.S.; Rabanal, M.E.; Dramicanin, M.; Milosevic, O. Photoluminescent properties of nanostructured $\mathrm{Y}_{2} \mathrm{O}_{3}: \mathrm{Eu}^{3+}$ powders obtained through aerosol synthesis. Opt. Mater. 2010, 32, 1606-1611. [CrossRef]

102. Lojpur, V.; Nikolic, M.; Mancic, L.; Milosevic, O.; Dramicanin, M.D. Up-conversion luminescence in $\mathrm{Ho}^{3+}$ and $\mathrm{Tm}^{3+}$ co-doped $\mathrm{Y}_{2} \mathrm{O}_{3}: \mathrm{Yb}^{3+}$ fine powders obtained through aerosol decomposition. Opt. Mater. 2012, 35, 38-44. [CrossRef]

103. Meza-Rocha, A.N.; Huerta, E.F.; Zaleta-Alejandre, E.; Rivera-Álvarez, Z.; Falcony, C. Enhanced photoluminescence of $\mathrm{Y}_{2} \mathrm{O}_{3}: \mathrm{Er}^{3+}$ thin films by $\mathrm{Li}^{+}$co-doping. J. Lumin. 2013, 141, 173-176. [CrossRef]

104. Meza-Rocha, A.N.; Canto, C.; Andrade, E.; De Lucio, O.; Huerta, E.F.; González, F.; Rocha, M.F.; Falcony, C. Visible and near infra-red luminescent emission from $\mathrm{Y}_{2} \mathrm{O}_{3}: \mathrm{Er}^{3+}$ films co-doped with $\mathrm{Li}^{+}$and their elemental composition by ion beam analysis. Ceram. Int. 2014, 40, 14647-14653. [CrossRef] 
105. Meza-Rocha, A.N.; Huerta, E.F.; Caldiño, U.; Zaleta-Alejandre, E.; Murrieta-S, H.; Hernández-A, J.M.; Camarillo, E.; Rivera-Álvarez, Z.; Righini, G.C.; Falcony, C. $\mathrm{Li}^{+}$co-doping effect on the photoluminescence time decay behavior of $\mathrm{Y}_{2} \mathrm{O}_{3}: \mathrm{Er}^{3+}$ films. J. Lumin. 2014, 154, 106-110. [CrossRef]

106. Alarcón-Flores, G.; García-Hipólito, M.; Aguilar-Frutis, M.; Carmona-Téllez, S.; Martinez-Martinez, R.; Campos-Arias, M.P.; Jiménez-Estrada, M.; Falcony, C. Luminescent and Structural Characteristics of $\mathrm{Y}_{2} \mathrm{O}_{3}: \mathrm{Tb}^{3+}$ Thin Films as a Function of Substrate Temperature. ECS J. Solid State Sci. Technol. 2014, 3, R189-R194. [CrossRef]

107. Alarcón-Flores, G.; García-Hipólito, M.; Aguilar-Frutis, M.; Carmona-Téllez, S.; Martinez-Martinez, R.; Campos-Arias, M.P.; Zaleta-Alejandre, E.; Falcony, C. Synthesis and fabrication of $\mathrm{Y}_{2} \mathrm{O}_{3}: \mathrm{Tb}^{3+}$ and $\mathrm{Y}_{2} \mathrm{O}_{3}: \mathrm{Eu}^{3+}$ thin films for electroluminescent applications: Optical and structural characteristics. Mater. Chem. Phys. 2015, 149-150, 34-42. [CrossRef]

108. Jayaramaiah, J.R.; Nagabhushana, K.R.; Lakshminarasappa, B.N. Effect of lithium incorporation on luminescence properties of nanostructured $\mathrm{Y}_{2} \mathrm{O}_{3}: \mathrm{Sm}^{3+}$ thin films. J. Anal. Appl. Pyrolysis 2017, 123, 229-236. [CrossRef]

109. Nanto, H.; Minami, T.; Takata, S. Photoluminescence in sputtered ZnO thin films. Phys. Status Solidi A 1981, 65, K131-K134. [CrossRef]

110. Falcony, C.; Ortiz, A.; García, M.; Helman, J.S. Photoluminiscence characteristics of undoped and terbium chloride doped zinc oxide films deposited by spray pyrolysis. J. Appl. Phys. 1988, 63, 2378-2381. [CrossRef]

111. Studenikin, S.A.; Golego, N.; Cocivera, M. Fabrication of green and orange photoluminescent, undoped ZnO films using spray pyrolysis. J. Appl. Phys. 1998, 84, 2287-2294. [CrossRef]

112. Ortiz, A.; García, M.; Falcony, C. Lithium doped zinc oxide photoluminescence films prepared by spray pyrolysis. Mater. Chem. Phys. 1990, 24, 383-388. [CrossRef]

113. Ortiz, A.; García, M.; Falcony, C. Photoluminescent properties of indium-doped zinc oxide films prepared by spray pyrolysis. Thin Solid Films 1992, 207, 175-180. [CrossRef]

114. Vanheusden, K.; Seager, C.H.; Warren, W.L.; Tallant, D.R.; Caruso, J.; Hampden-Smith, M.J.; Kodas, T.T. Green photoluminescence efficiency and free-carrier density in $\mathrm{ZnO}$ phosphor powders prepared by spray pyrolysis. J. Lumin. 1997, 75, 11-16. [CrossRef]

115. Ortiz, A.; Falcony, C.; Hernández A, J.; García, M.; Alonso, J.C. Photoluminescent characteristics of lithium doped zinc oxide films deposited by spray pyrolysis. Thin Solid Films 1997, 293, 103-107. [CrossRef]

116. Yoon, K.H.; Cho, J.Y. Photoluminescence characteristics of zinc oxide thin films prepared by spray pyrolysis technique. Mater. Res. Bull. 2000, 35, 39-46. [CrossRef]

117. El Hichou, A.; Bougrine, A.; Bubendorff, J.L.; Ebothé, J.; Addou, M.; Troyon, M. Structural, optical and cathodoluminescence characteristics of sprayed undoped and fluorine-doped $\mathrm{ZnO}$ thin films. Semicond. Sci. Technol. 2002, 17, 607-613. [CrossRef]

118. Bougrine, A.; El Hichou, A.; Addou, M.; Ebothé, J.; Kachouane, A.; Troyon, M. Structural, optical and cathodoluminescence characteristics of undoped and tin-doped $\mathrm{ZnO}$ thin films prepared by spray pyrolysis. Mater. Chem. Phys. 2003, 80, 438-445. [CrossRef]

119. Panatarani, C.; Lenggoro, I.W.; Okuyama, K. The crystallinity and the photoluminescent properties of spray pyrolized $\mathrm{ZnO}$ phosphor containing $\mathrm{Eu}^{2+}$ and $\mathrm{Eu}^{3+}$ ions. J. Phys. Chem. Solids 2004, 65, 1843-1847. [CrossRef]

120. Ratheesh Kumar, P.M.; Vijayakumar, K.P.; Sudha Kartha, C. On the origin of blue-green luminescence in spray pyrolysed ZnO thin films. J. Mater. Sci. 2007, 42, 2598-2602. [CrossRef]

121. Choi, M.H.; Ma, T.Y. Erbium concentration effects on the structural and photoluminescence properties of ZnO:Er films. Mater. Lett. 2008, 62, 1835-1838. [CrossRef]

122. Liu, K.; Yang, B.F.; Yan, H.; Fu, Z.; Wen, M.; Chen, Y.; Zuo, J. Strong room-temperature ultraviolet emission from nanocrystalline $\mathrm{ZnO}$ and $\mathrm{ZnO}: \mathrm{Ag}$ films grown by ultrasonic spray pyrolysis. Appl. Surf. Sci. 2008, 255, 2052-2056. [CrossRef]

123. Bouzid, K.; Djelloul, A.; Bouzid, N.; Bougdira, J. Electrical resistivity and photoluminescence of zinc oxide films prepared by ultrasonic spray pyrolysis. Phys. Status Solidi A 2009, 206, 106-115. [CrossRef]

124. Behera, D.; Acharya, B.S. Study of the microstructural and photoluminescence properties of Li-doped ZnO thin films prepared by spray pyrolysis. Ionics 2010, 16, 543-548. [CrossRef]

125. Soumahoro, I.; Schmerber, G.; Douayar, A.; Colis, S.; Abd-Lefdil, M.; Hassanain, N.; Berrada, A.; Muller, D.; Slaoui, A.; Rinnert, H.; et al. Structural, optical, and electrical properties of Yb-doped ZnO thin films prepared by spray pyrolysis method. J. Appl. Phys. 2011, 109, 033708. [CrossRef] 
126. Shinde, S.S.; Shinde, P.S.; Oh, Y.W.; Haranath, D.; Bhosale, C.H.; Rajpure, K.Y. Investigation of structural, optical and luminescent properties of sprayed N-doped zinc oxide thin films. J. Anal. Appl. Pyrolysis 2012, 97, 181-188. [CrossRef]

127. Shinde, S.S.; Shinde, P.S.; Oh, Y.W.; Haranath, D.; Bhosale, C.H.; Rajpure, K.Y. Structural, optoelectronic, luminescence and thermal properties of Ga-doped zinc oxide thin films. Appl. Surf. Sci. 2012, 258, 9969-9976. [CrossRef]

128. Tomakin, M. Structural and optical properties of $\mathrm{ZnO}$ and $\mathrm{Al}$-doped $\mathrm{ZnO}$ microrods obtained by spray pyrolysis method using different solvents. Superlattices Microstruct. 2012, 51, 372-380. [CrossRef]

129. Bayoud, S.; Addou, M.; Bahedi, K.; El Jouad, M.; Sofiani, Z.; Lamrani, M.A.; Bernéde, J.C.; Ebothé, J. The lithium effect on the blue and red emissions of Er-doped zinc oxide thin films. Phys. Scr. 2013, T157, 014045. [CrossRef]

130. Panatarani, C.; Muharam, D.G.; Wibawa, B.M.; Joni, I.M. Blue Luminescence of ZnO:Zn Nanocrystal Prepared by One Step Spray Pyrolysis Method. Mater. Sci. Forum 2013, 737, 20-27. [CrossRef]

131. Velázquez Lozada, E.; Torchynska, T.V.; Casas Espinola, J.L.; Pérez Millan, B. Emission of ZnO:Ag nanorods obtained by ultrasonic spray pyrolysis. Phys. B 2014, 453, 111-115. [CrossRef]

132. Vijayalakshmi, K.; Karthick, K. The Role of Substrates on the Structural, Optical, and Morphological Properties of ZnO Nanotubes Prepared by Spray Pyrolysis. Microsc. Res. Tech. 2014, 77, 211-215. [CrossRef] [PubMed]

133. Kumar, V.; Ntwaeaborwa, O.M.; Soga, T.; Dutta, V.; Swart, H.C. Rare Earth Doped Zinc Oxide Nanophosphor Powder: A Future Material for Solid State Lighting and Solar Cells. ACS Photonics 2017, 4, 2613-2637. [CrossRef]

134. Angulo-Rocha, J.; Velarde-Escobar, O.; Yee-Rendón, C.; Atondo-Rubio, G.; Millan-Almaraz, R.; Camarillo-García, E.; García-Hipólito, M.; Ramos-Brito, F. Morphological, structural and optical properties of $\mathrm{ZnO}$ thin solid films formed by nanoleafs or micron/submicron cauliflowers. J. Lumin. 2017, 185, 306-315. [CrossRef]

135. Narayanan, N.; Deepak, N.K. Enhancement of visible luminescence and photocatalytic activity of ZnO thin films via Cu doping. Optik 2018, 158, 1313-1326. [CrossRef]

136. Karakaya, S. Effect of fluorine and boron co-doping on $\mathrm{ZnO}$ thin films: Structural, luminescence properties and Hall effect measurements. J. Mater. Sci.: Mater. Electron. 2018, 29, 4080-4088. [CrossRef]

137. Ortiz, A.; Falcony, C.; García, M.; Sánchez, A. Zinc sulphide films doped with terbium chloride and samarium chloride, prepared by spray pyrolysis. Semicond. Sci. Technol. 1988, 3, 537-541. [CrossRef]

138. Ortiz, A.; García, M.; Sánchez, A.; Falcony, C. Spray pyrolysis deposition of In, Al and Cu doped ZnS photoluminiscent films. J. Electrochem. Soc. 1989, 136, 1232-1235. [CrossRef]

139. Falcony, C.; García, M.; Ortiz, A.; Alonso, J.C. Luminescent properties of ZnS:Mn films deposited by spray pyrolysis. J. Appl. Phys. 1992, 72, 1525-1527. [CrossRef]

140. Liu, S.; Zhang, H.; Swihart, M.T. Spray pyrolysis synthesis of ZnS nanoparticles from a single-source precursor. Nanotechnology 2009, 20, 235603. [CrossRef] [PubMed]

(C) 2018 by the authors. Licensee MDPI, Basel, Switzerland. This article is an open access article distributed under the terms and conditions of the Creative Commons Attribution (CC BY) license (http:// creativecommons.org/licenses/by/4.0/). 